Article

\title{
Study on Three-Dimensional Stress Field of Gob-Side Entry Retaining by Roof Cutting without Pillar under Near-Group Coal Seam Mining
}

\author{
Xiaoming Sun ${ }^{1,2, *, \dagger}$, Yangyang Liu ${ }^{1,2, *, \dagger}$, Junwei Wang ${ }^{1,2}$, Jiangbing $\mathrm{Li}^{1,2}$, Shijie Sun ${ }^{1,2}$ and \\ Xuebin Cui ${ }^{1,2}$ \\ 1 State Key Laboratory for Geomechanics \& Deep Underground Engineering, China University of Mining \& \\ Technology, Beijing 100083, China \\ 2 School of Mechanics and Civil Engineering, China University of Mining \& Technology, Beijing 100083, China \\ * Correspondence: zqt1700620120g@student.cumtb.edu.cn (X.S.); \\ zqt1700620112g@student.cumtb.edu.cn (Y.L.); Tel.: +86-180-3922-5611 (X.S.) \\ + These authors contributed equally to this work.
}

Received: 13 June 2019; Accepted: 16 August 2019; Published: 22 August 2019

check for updates

\begin{abstract}
In order to explore the distribution law of stress field under the mining mode of gob-side entry retaining by roof cutting without pillar (GERRCP) under goaf, based on the engineering background of 8102 and 9101 working faces in Xiashanmao coal mine, the stress field distribution of GERRCP and traditional remaining pillar was studied by means of theoretical analysis and numerical simulation. The simulation results showed that: (1) in the front of the working face, the vertical peak stress of non-pillar mining was smaller than that of the remaining pillar mining, and it could effectively control stress concentration in surrounding rock of the mining roadway; the trend of horizontal stress distribution of the two was the same, and the area, span and peak stress of stress the rise zone were the largest in large pillar mining and the minimum in non-pillar mining. (2) On the left side of the working face, the vertical stress presented increasing-decreasing characteristics under non-pillar mining mode and saddle-shaped distribution characteristics under the remaining pillar mining mode respectively. Among them, the peak stress was the smallest under non-pillar mining, and compared with the mining of the large pillar and small pillar, non-pillar mining decreased by $12-21 \%$ and $3-10 \%$ respectively. The position of peak stress of the former was closer to the mining roadway, indicating that the width of the plastic zone of the surrounding rock of the non-pillar mining was smaller and bearing capacity was higher. In the mining of the large and small pillar, the horizontal stress formed a high stress concentration in the pillar and 9102 working face respectively. In non-pillar mining, the horizontal stress concentration appeared in solid coal, but the concentration area was small.
\end{abstract}

Keywords: non-pillar; gob-side entry retaining by roof cutting; close distance coal seams; goaf; stress distribution

\section{Introduction}

In the 1960s and 1970s, longwall mining technology developed rapidly, and the "masonry beam theory" was put forward, forming the "121" construction method of longwall mining [1]. This technology requires two roadways to be tunneled for each working face, and a large pillar is set up to balance underground pressure. The "transfer rock beam theory" was put forward by analyzing the existence of the internal and external stress field in a high-stress area, forming the " 121 " small pillar construction method of longwall mining [2,3]. However, the traditional mining method of " 121 " will form a hanging roof with insufficient collapse at the side of the goaf, and the roof subsidence and 
rotary deformation are large, which greatly affects the stability of the pillar and support system on roadway side. In order to reduce the development ratio, increase the coal mining rate and improve the periodic pressure of roof, the "cutting cantilever beam theory" was born [4], and based on this theory, the mining technology of gob-side entry retaining by roof cutting without pillar (GERRCP) was proposed. In the new mining technology of GERRCP, only one roadway needs to be tunneled for each working face, and the other roadway is formed automatically by roof cutting and pressure relief. Moreover, there is no need to leave pillars, which reduces the waste of coal resources and avoids roof accidents, rock burst, gas outburst and other safety hazards caused by remaining pillars [5]. The phenomenon of stress concentration caused by a pillar is eliminated, and the pressure distribution of a stope is optimized, which makes coal mining more safe and efficient. Many scholars have carried out a lot of related research work on GERRCP using theoretical analysis, numerical simulation, laboratory experiments and field experiments. As one of the powerful methods, the numerical simulation has the advantage of low cost, high efficiency and good repeatability. It has been widely used in the related research of this technology and achieved good application results. With the introduction of GERRCP, its design principle and key technologies have been extensively investigated [6-8]. Guo et al. [9] studied the relationship between roof fracturing angle and stability of gob-side entry subjected to dynamic loading through establishing a numerical calculation model. Zhen et al. [10] investigated the influence of two methods of non-pillar-mining techniques by roof cutting and by filling artificial materials on the results of the entry retained via industrial case and numerical simulation. Guo et al. [11] studied the roof pre-fracturing and energy-absorbing support systems to evaluate the stress distribution and deformation control of gob-side entry by numerical simulation. Hu et al. [12] investigated the key parameters affecting GERRCP by theoretical analysis and numerical simulation. Combined with the above research, it can be found that the above researches on GERRCP were carried out under the condition of single coal-seam mining, and few researches on this technology when mining close distance coal seam. Therefore, it is of great significance to carry out relevant researches on GERRCP under the condition of near-group coal-seam mining.

The near-group coal-seam mining is very characteristic. When mining close distance coal-seam, the roof caving of the upper coal seam will cause various degrees of damage to the roof of the lower coal seam. As a result, the upper overburden structure and temporal and spatial distribution characteristics of the stress field during the mining of the lower coal seam are significantly different from those of a single coal seam. In particular, the mining direction of the lower coal seam is perpendicular to that of the upper coal seam, forming the vertical cross mining. Therefore, in order to ensure the safety of coal mining, it is of significance to analyze the distribution law of the stress field in lower coal seam when mining close distance coal seam. At present, domestic and foreign experts and scholars have conducted a lot of studies on the distribution law of a stress field in lower coal seam when mining close distance coal seam, and achieved fruitful results. Singh [13] established a numerical model and combined it with a double-yield model to assess its effectiveness in simulating the recovery of stress in goaf. Through theoretical analyses and physical modelling studies, the interaction between vertical stress distribution within goaf and surrounding rock mass in these systems was studied [14]. Zhang et al. [15] investigated the stress distribution, fracture development, and strata movement above a protective coal seam in longwall mining through numerical calculation. Liu et al. [16] analysed the stress distribution and roadway position of lower seams in the close distance coal seams by using numerical simulation. Zhang et al. [17] studied the floor failure depth of upper coal seam during close coal seams mining by building the mechanical model of floor failure of upper coal seam. Xu et al. [18] studied the stress propagation and distribution of a roadway by Kirsch equations and analyzed the changes of stress, displacement, and plastic zones around roadways during the mining of the upper coal seams by means of numerical simulation. Wang et al. [19] analyzed some key issues about abutment pressure and stress concentration shell by numerical simulations to study the distribution and evolution characteristics of the macroscopic stress field of surrounding rocks. Ma et al. [20] studied the stress distribution and deformation law of surrounding rocks for the water-dripping roadway below a contiguous seam goaf. 
In-depth studies on the movement and instability characteristics and mining stress evolution law of the secondary mining structure of roof under goaf, were carried out by means of theoretical analysis, similarity simulation experiment, numerical simulation and field measurement [21-24].

The above experts and scholars have achieved fruitful results in research on the distribution law of a stress field when mining near-group coal seam. However, most previous studies have focused on conventional mining methods; few scholars have carried out relevant research on the stress distribution of the stope in GERRCP in the near-group coal-seam mining. In order to explore the distribution law of three-dimensional stress field of GERRCP in the near-group coal seam mining, this paper takes Xiashanmao coal mine as an engineering background, establishes the mechanical model of the roof structure of GERRCP through theoretical analysis, and establishes a three-dimensional numerical calculation model based on the finite difference program FLAC-3D (ITASCA, US) to study the distribution law of stress in the stope. Finally, the numerical simulation results are validated by field experiments.

\section{Gob-Side Entry Retaining by Roof Cutting without Pillar (GERRCP)}

\subsection{Principle of GERRCP}

As shown in Figure 1, the GERRCP adopts energy-gathered blasting technology to carry out advanced pre-splitting on the roof. The roof is cut off along the pre-splitting damaged structural surface through periodic weighting of the stope, and the fractured roof collapses naturally with the help of underground pressure. The side of the roadway is formed by the broken expanded characteristic of the collapsed gangue, and the flexible support body in a roadway is formed by the sliding and yielding gangue support structure and constant pressure retractable support equipment, which separates the goaf. At the same time, the high strength support of a roadway roof is formed by the constant-resistance large-deformation anchor cable (CRLDAC) with structural characteristics of negative Poisson's ratio, thus realizing the non-pillar mining of a single working face and single roadway $[25,26]$. This technology realizes the transformation of a roadway roof structure from a long-wall beam to short-wall beam by roof cutting, which ensures the stability of the roadway, can weaken the concentrated stress on the upper part of the coal body adjacent to working face, and can also avoid the roof collapse, rock burst and gas outburst caused by remaining pillars.

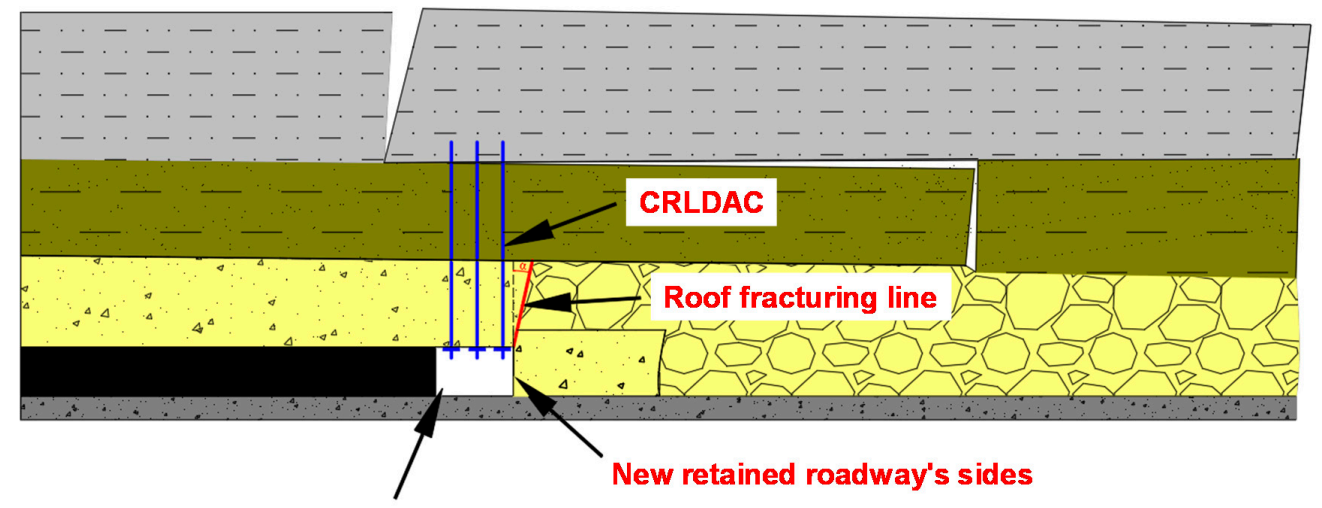

Automatically formed roadway

Figure 1. Section diagram of roof structure of gob-side entry retaining by roof cutting without pillar (GERRCP).

The mechanical model of the roof structure of GERRCP is introduced below (as shown in Figure 2). Under the action of periodic pressure, the immediate roof and main roof fracture and rotate. The main roof is fractured to form rock blocks A, B and C, and the interaction between the rock blocks forms a hinge structure. Rock block $A$ is still supported by the immediate roof, which is relatively stable. Rock block $C$ is supported by the gangue on the side of the goaf, and its stability is poor. Both ends 
of rock block B are supported by the immediate roof and gangue in the goaf, respectively, and rotate towards the goaf around the elastic-plastic boundary of solid coal. The following assumptions are made for the mechanical model of surrounding rock: (1) there is no interaction between rock block $\mathrm{B}$ and $\mathrm{C}$ and the gangue at the side of the goaf; (2) the shear force between rock strata such as immediate roof and main roof is ignored; (3) the supporting capacity of coal body in the lateral plastic zone of the retaining roadway is not considered; (4) the supporting force at the side of the roadway is neglected. The structural mechanical model established according to the assumed conditions is shown in Figure 2 .

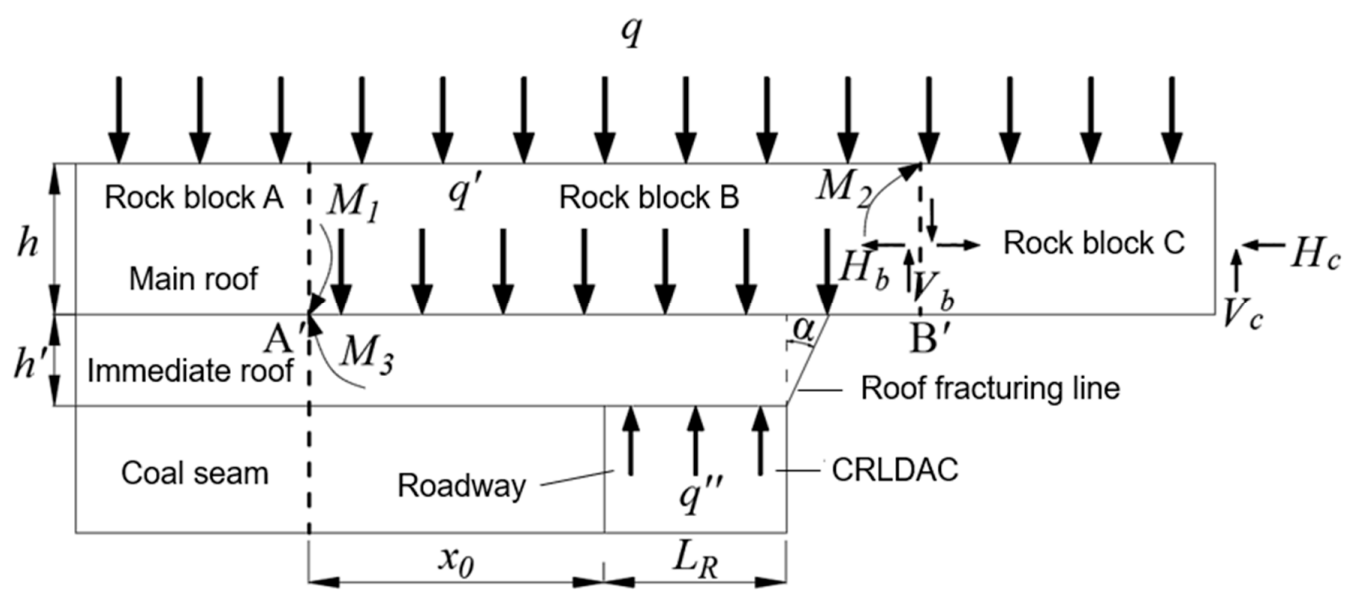

Figure 2. Mechanical model of roof structure of GERRCP.

The above picture is explained as follows. The key parameters of the system are as follows. After the rock strata fracture, the fracture length of key block B formed is [27]:

$$
L=L_{s}\left(\sqrt{\frac{L_{s}^{2}}{L_{f}^{2}}+\frac{3}{2}}-\frac{L_{s}}{L_{f}}\right)
$$

where, $L$ : length of rock block; $L_{s}$ : weighting interval of the immediate roof; $L_{f}$ : working face length.

The horizontal force on rock block $\mathrm{B}$ is

$$
H_{b}=\frac{q L}{2\left(h-S_{b}\right)}
$$

where, $H_{b}$ : horizontal force on rock block $\mathrm{B} ; q$ : uniform load acting on the main roof; $h$ : the thickness of basic roof; and $S_{b}$ : the subsidence of rock block B.

The research on the mechanism of arch effect and its boundary conditions was studied, and the calculation of the plastic zone was referenced, and the width of the stress limit equilibrium zone in coal body was obtained $[27,28]$.

$$
x_{0}=\frac{h_{r} A}{2 \tan \varphi_{0}} \ln \left(\frac{k \gamma H+\frac{c_{0}}{\tan \varphi_{0}}}{\frac{c_{0}}{\tan \varphi_{0}}+\frac{p_{x}}{A}}\right)
$$

where, $x_{0}$ : width of stress limit equilibrium zone in coal body; $h_{r}$ : roadway height; $A$ : lateral pressure coefficient; $C_{0}$ : cohesion of the interface between coal and rock; $\varphi_{0}$ : internal friction angle; $K$ : stress concentration factor; $\gamma$ : average bulk density of overburden; $H$ : roadway burial depth; $P_{x}$ : support resistance of coal sides.

After mining, the main roof structure breaks under periodic pressure, forming a hinge structure, and the structure is in equilibrium. Through static analysis of hinge structure under this equilibrium condition, the static equilibrium equations of rock block $C$ and $B$ are established, such as Formulas 4 and 5. Among them, the support force provided by the support body in the roadway is simplified 
as the load collection degree of support, and the support load in the roadway is solved based on the above analysis.

(1) Rock block C:

$$
\begin{gathered}
\Sigma X=0, H_{b}-H_{c}=0 \\
\Sigma Y=0, q L+V_{b}-V_{c}=0 \Sigma M_{B^{\prime}}=0,-M_{2}+H_{c}\left(h / 2-S_{c}\right)+V_{c} L-H_{b}\left(h / 2-S_{c}\right)-q L^{2} / 2=0
\end{gathered}
$$

where, $H_{c}$ : horizontal force on rock block $C ; V_{c}$ : the vertical force on rock block $C ; V_{b}$ : the vertical force on rock block B; $M_{2}$ : moment of rock block $\mathrm{C}$ at section $\mathrm{B}$; and $S_{c}$ : the subsidence of rock block $\mathrm{C}$.

(2) Rock block B:

$$
\begin{gathered}
\Sigma M_{A^{\prime}}=0,-M_{1}-M_{3}+q^{\prime \prime} L_{R}\left(x_{0}+L_{R} / 2\right)+H_{b}\left(h / 2-S_{b}\right)-q L^{2} / 2+M_{2}+V_{b} L+q^{\prime}\left(x_{0}+L_{R}+h^{\prime} \tan \alpha\right) \\
{\left[\left(L_{R}+x_{0}\right)^{2}+\left(x_{0}+L_{R}+h^{\prime} \tan \alpha\right)^{2}+\left(L_{R}+x_{0}\right)\left(x_{0}+L_{R}+h^{\prime} \tan \alpha\right)\right] / 3\left(2 x_{0}+2 L_{R}+h^{\prime} \tan \alpha\right)=0}
\end{gathered}
$$

where, $M_{1}$ : moment of rock block B at section $\mathrm{A} ; M_{3}$ : moment of immediate roof to basic roof; $q^{\prime \prime}$ : load collection degree of support in the roadway; $L_{R}$ : roadway width; $q^{\prime}$ : the uniform load acting on the immediate roof; $h^{\prime}$ : the thickness of immediate roof; and $\alpha$ : pre-cracking roof cutting angle.

(3) The load collection degree of support in the roadway can be obtained simultaneously.

$$
q^{\prime \prime}=\left\{\begin{array}{c}
M_{1}+M_{3}-2 M_{2}+q L^{2}-q L\left(h-2 S_{b}\right) / 4\left(h-S_{b}\right)-q^{\prime}\left(x_{0}+L_{R}+h^{\prime} \tan \alpha\right) \\
{\left[\left(2 x_{0}+2 L_{R}+h^{\prime} \tan \alpha\right)^{2}-\left(x_{0}+L_{R}\right)\left(x_{0}+L_{R}+h^{\prime} \tan \alpha\right)\right] / 3\left(2 x_{0}+2 L_{R}+h^{\prime} \tan \alpha\right)}
\end{array}\right\} / L_{R}\left(x_{0}+L_{R} / 2\right)
$$

Based on the new technology of GERRCP, the mechanical model of the roof structure is established. Through the mechanical analysis of the model, the key parameters such as fracture length of key blocks in upper strata and horizontal force acting on it are introduced, and the extension depth of the plastic zone in the solid coal side of the roadway under this technical condition is obtained, which provides certain theoretical support for the support design of the solid coal side of the mining roadway. In addition, through the static analysis of the balanced hinge structure under the condition of GERRCP, the corresponding static equilibrium equation is established, and the support load in roadway under this condition is obtained, which provides corresponding theoretical support for the support problem of mining roadway.

\subsection{Technical Process of GERRCP}

The mining mode layout of the traditional "121" construction method is shown in Figure 3a. When the mining system is used for coal mining, pillars are left, which belongs to the mining method of "one working face and two roadways". Different from the traditional mining method, the GERRCP is shown in Figure $3 b$, which is a typical single working face and single roadway without a pillar mining method. That is to say, the up and down drifts on the first face should be excavated firstly, and then at the same time in the working face of the mining, the retaining roadway, as the transport roadway on the next working face, is formed through the reinforcement of the advance anchor cable, pre-cracking roof cutting and gangue support at the side of the goaf. Therefore, the mining ratio is reduced and non-pillar mining is realized.

The technological process of GERRCP is shown in Figure 4. Its core can be summarized as four steps: strengthening, cutting, protecting and closing, that is: (1) adopt the CRLDAC to actively strengthen the supporting roadway roof according to the designed supporting parameters (Figure 4a); (2) the energy-gathered pre-cracking blasting hole shall be constructed at a certain distance in advance of the working face, and the bidirectional energy-gathered pre-cracking blasting shall be carried out according to the parameters determined by the blasting test to form a slit on the roof at the side of the goaf (Figure $4 \mathrm{~b}$ ); (3) after mining at the working face, the sliding and yielding gangue support structure and the constant pressure retractable support equipment are adopted behind the working face to strengthen the support in time. Under the action of the underground pressure, the roof at the side of the goaf collapses along the structural surface of the roof cutting slit to form the side of a new 
roadway (Figure 4c); (4) the caving roof is gradually compacted as the working face advances, and the side of the roadway formed by caving is shotcreted to close the goaf. After the roadway is stabilized, the temporary support equipment is removed to realize the retaining new roadway (Figure $4 \mathrm{~d}$ ).

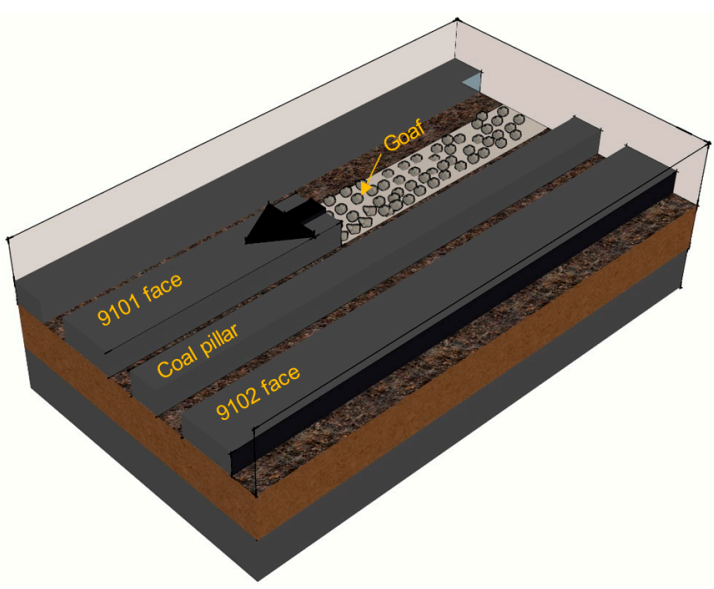

(a)

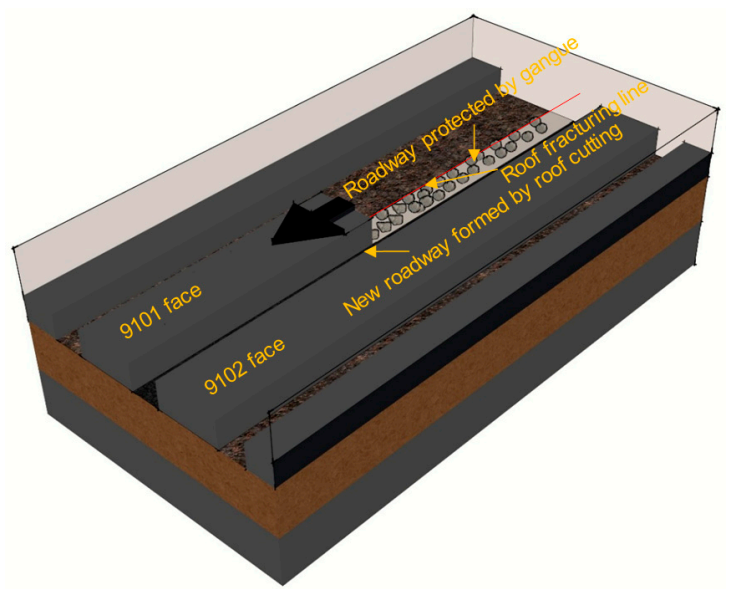

(b)

Figure 3. Layout of mining mode. (a) Layout of traditional mining mode; (b) Layout of non-pillar mining mode.

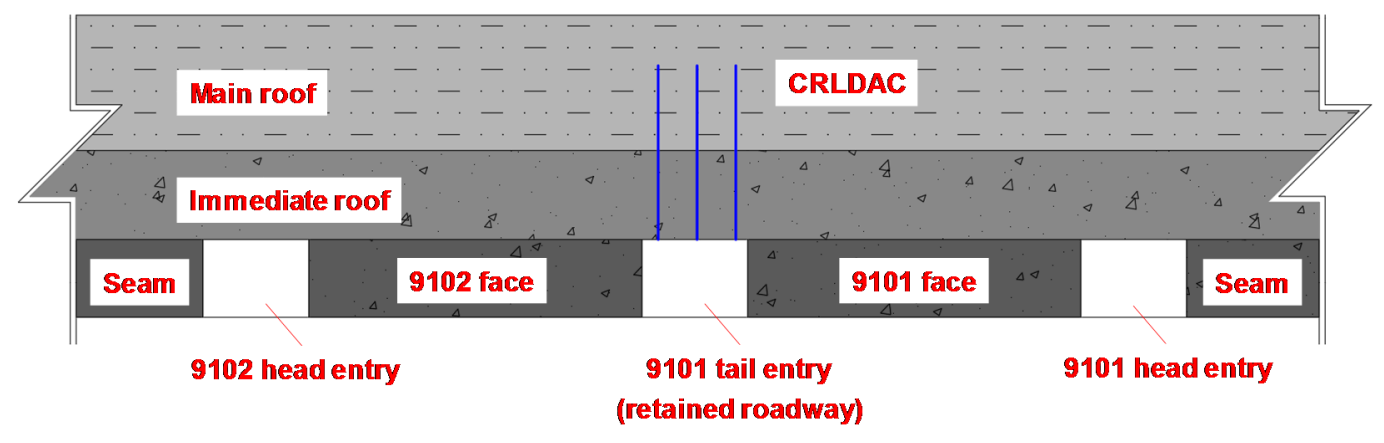

(a)

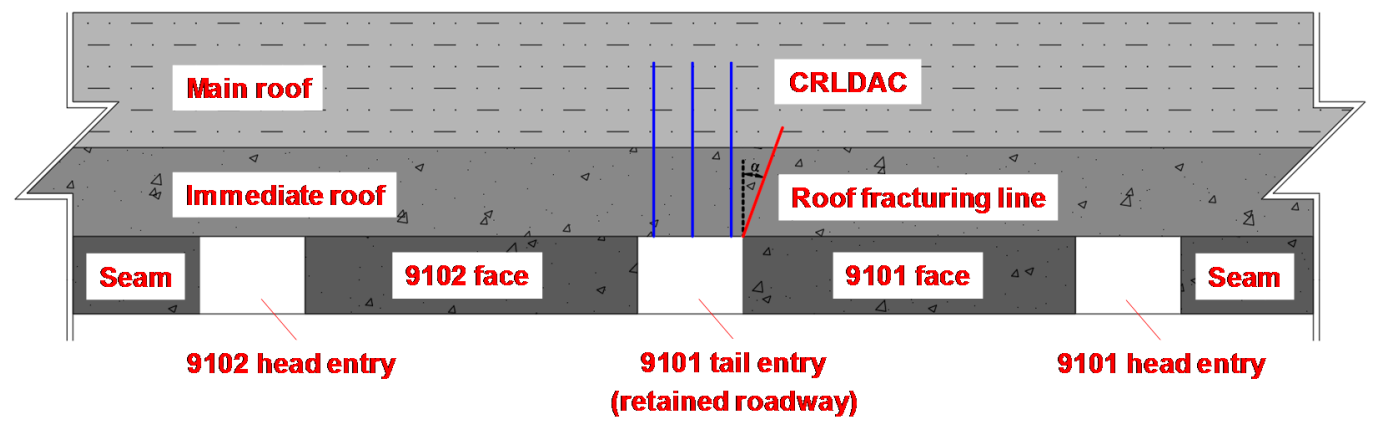

(b)

Figure 4. Cont. 


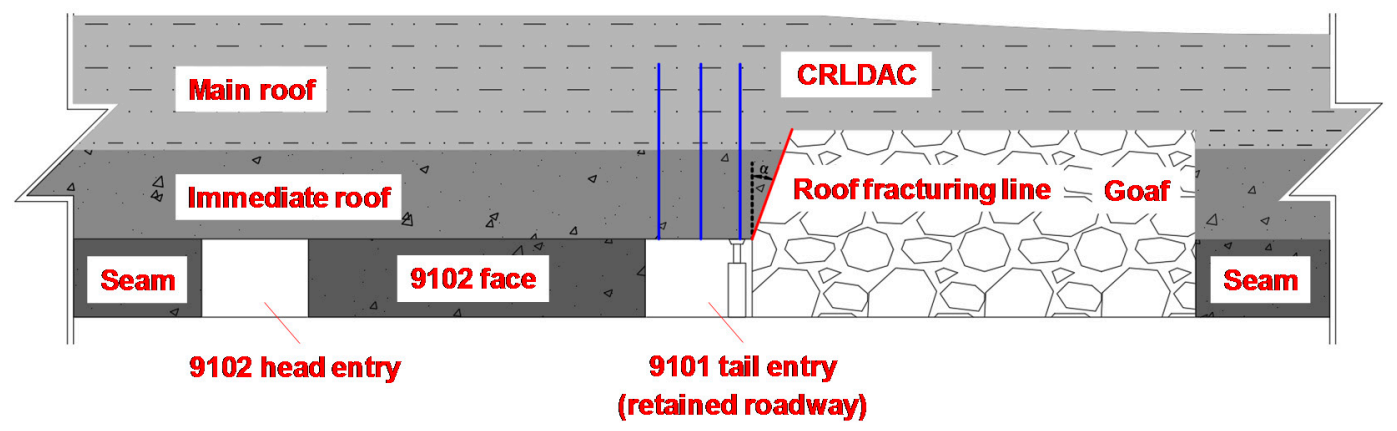

(c)

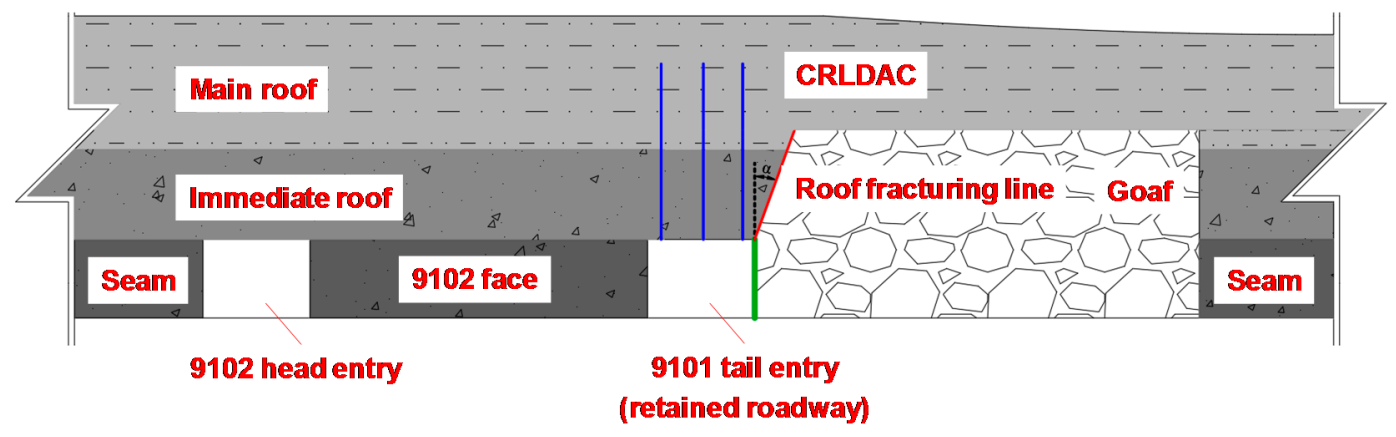

(d)

Figure 4. Technological process of GERRCP. (a) Strengthening roadway roof by constant-resistance large-deformation anchor cable (CRLDAC); (b) Pre-cracking roof cutting by energy-gathered blasting; (c) Gangue support; (d) Closing the goaf by shotcreting.

\section{Engineering Background}

The coal seam in the 9101 working face of Xiashanmao coal mine is located in the lower part of Taiyuan Formation. The thickness of the coal seam is 1.55-3.5 m, and the designed mining height is $3 \mathrm{~m}$, which belongs to the medium-thick coal seam mining face. The dip angle of coal seam is $2-8^{\circ}$ and the buried depth is $180-260 \mathrm{~m}$. The distance between 8 \# coal seam and 9 \# coal seam is $11.20-19.60 \mathrm{~m}$, with an average of $15.24 \mathrm{~m}$. The immediate roof is mudstone, with an average thickness of $4.1 \mathrm{~m}$; the basic roof is mainly sandy mudstone with an average thickness of $8.0 \mathrm{~m}$, according to the drilling measurement on the roof and floor of the working face. The immediate and basic bottoms are mudstone and fine sandstone, respectively, as shown in Table 1.

Table 1. Lithological characteristics of roof and floor of coal seam.

\begin{tabular}{cccc}
\hline Name of Roof and Floor & Lithology & Thickness/m & Feature Description \\
\hline Main roof & Sandy mudstone & $4.6-9.1$ & Grey, block structure \\
\hline Immediate roof & Mudstone & $3.6-4.2$ & Black, block structure \\
\hline \# coal seam & Coal seam & $2.8-3.1$ & $\begin{array}{c}\text { Black, vitreous luster, } \\
\text { occurrence stability }\end{array}$ \\
\hline Immediate bottom & Mudstone & $4.8-8.5$ & Grey, block structure \\
\hline Basic bottom & Fine sandstone & $13.2-26.6$ & $\begin{array}{c}\text { Grey, block structure, } \\
\text { horizontal joint }\end{array}$ \\
\hline
\end{tabular}

The test face is the first working face of the first mining area of 9 \# coal seams, with a strike length of $480 \mathrm{~m}$ and an inclination of $150 \mathrm{~m}$ (as showed in Figure 5). The roof is managed by all caving method, 
which adopts full-seam, comprehensive mechanized, and retreating mining methods. The average $12 \mathrm{~m}$ above the 9101 working face is the 8102 working face, which serves as the mining protective layer of 9101 working face. Among them, the 8102 working face adopts the "121" construction method of longwall mining, and the 9101 working face adopts the self-formed roadway without a pillar-mining system, and the mining direction is vertical intersection. The adjacent face is the 9102 working face, which is located at the south of the 9101 working face. The test roadway is the ventilation roadway of the 9101 working face. The roadway section is rectangular, with a width of $4000 \mathrm{~mm}$ and a height of $3200 \mathrm{~mm}$.
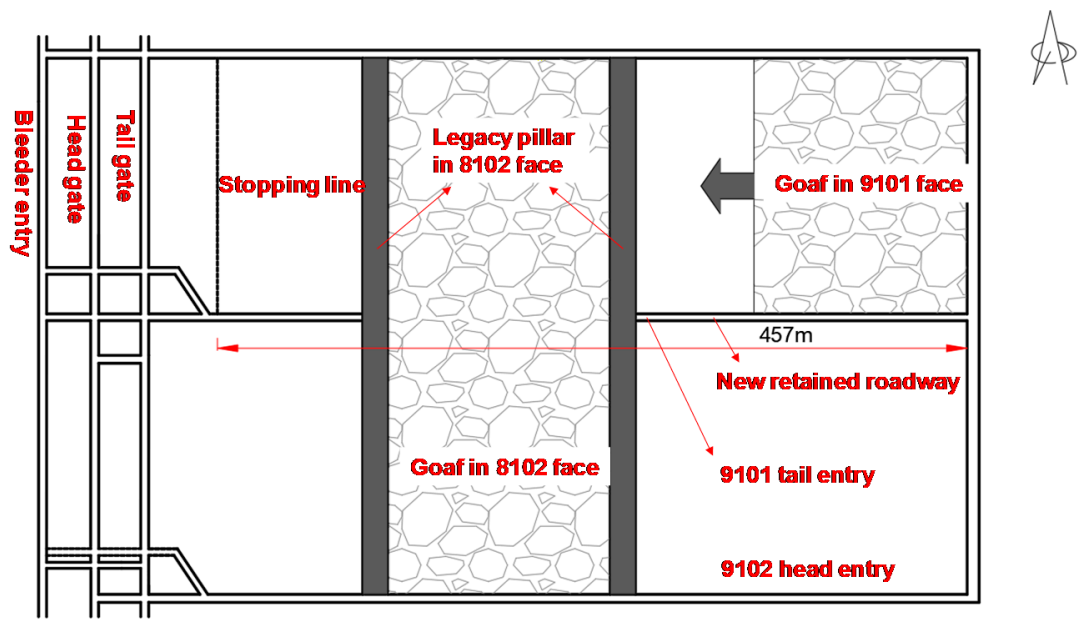

Figure 5. Layout of test working face of GERRCP in Xiashanmao coal mine.

\section{Numerical Calculation and Analysis}

\subsection{Construction of Numerical Model}

According to the specific engineering geological conditions of the 8102 and 9101 working faces of Xiashanmao coal mine, and combined with the existing underground pressure monitoring results, the finite difference software FLAC3D was used to establish a three-dimensional solid model. The distribution characteristics of mining stress in the mining process of the 9101 working face were studied. The numerical calculation model is shown in Figure 6. The calculation range was $330 \mathrm{~m} \times 230 \mathrm{~m} \times$ $100 \mathrm{~m}$ (length $\times$ width $\times$ height). The model simulated 12 layers of strata, including 8 \# coal seam, 9 \# coal seam and roof and floor strata, and truly reflected their occurrence conditions. Because the coal seam under actual working conditions could be regarded as a near-horizontal coal seam, the coal seam in the model was designed as a horizontal coal seam.

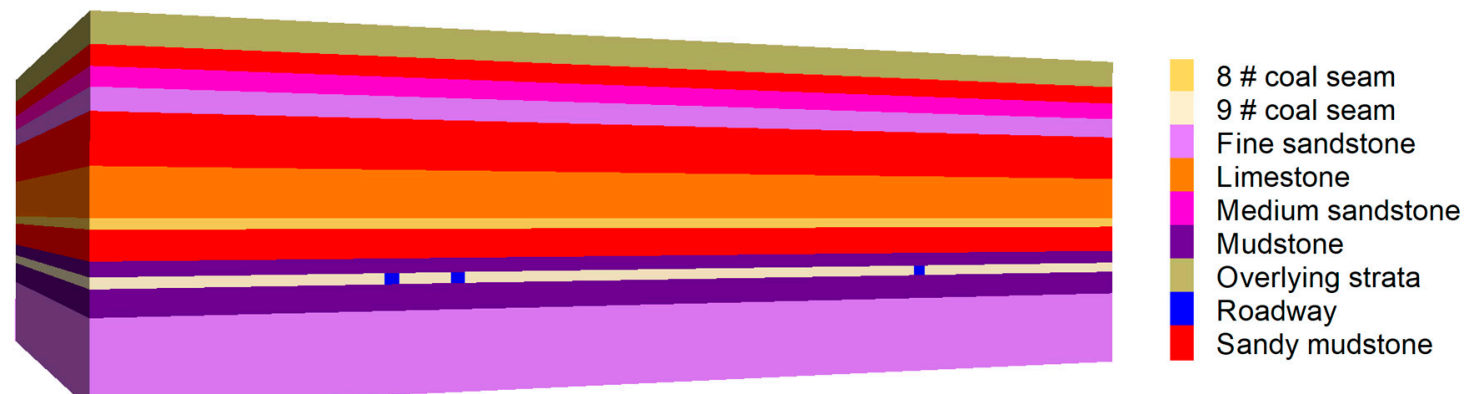

Figure 6. Three-dimensional numerical calculation model. 


\subsection{Determining Model Parameters}

For rock mass materials, the elastic modulus of rock mass greatly influences the accuracy of simulation results. Therefore, in the process of numerical simulation, the rock elastic modulus should be corrected and verified repeatedly to reduce the error with the actual value to ensure the reliability of simulation results. The physical and mechanical parameters of strata were obtained according to the test of rock core samples from geological drilling in the testing field, and the elastic modulus of rock was taken to be $1 / 10$ of the elastic modulus of rock block by comparing with the physical parameters of rock strata in the adjacent working face. In this study, the mole-coulomb model was selected as the constitutive model, and the effective physical and mechanical parameters of rock mass were finally determined based on the physical and mechanical parameters of the rock mass involved, as shown in Table 2.

Table 2. The physical and mechanical parameters of rock.

\begin{tabular}{ccccccc}
\hline Lithology & $\begin{array}{c}\text { Density } \\
\left(\mathbf{k g} \cdot \mathbf{m}^{-3} \mathbf{)}\right.\end{array}$ & $\begin{array}{c}\text { Bulk } \\
\text { Modulus } \\
\mathbf{( G P a )}\end{array}$ & $\begin{array}{c}\text { Shear } \\
\text { Modulus } \\
\mathbf{( G P a )}\end{array}$ & $\begin{array}{c}\text { Cohesion } \\
\mathbf{( M P a})\end{array}$ & $\begin{array}{c}\text { Internal } \\
\text { Friction } \\
\left.\text { Angle } \mathbf{(}^{\circ}\right)\end{array}$ & $\begin{array}{c}\text { Tensile } \\
\text { Strength } \\
\mathbf{( M P a})\end{array}$ \\
\hline $\begin{array}{c}\text { Upper strata } \\
\text { Sandy mudstone }\end{array}$ & 2620 & 6.47 & 4.09 & 1.61 & 35 & 0.82 \\
Medium Sandstone & 2512 & 12.36 & 7.21 & 2.04 & 33 & 0.74 \\
Fine sandstone & 2670 & 23.46 & 15.20 & 4.45 & 40 & 5.14 \\
Sandy mudstone & 2503 & 21.04 & 13.52 & 3.20 & 42 & 1.29 \\
Limestone & 2910 & 10.63 & 5.59 & 2.04 & 33 & 0.74 \\
8 \# coal seam & 1380 & 4.91 & 18.27 & 5.14 & 42 & 7.31 \\
Sandy mudstone & 2531 & 14.13 & 9.01 & 1.25 & 32 & 0.15 \\
Mudstone & 2488 & 9.97 & 7.35 & 4.35 & 33 & 0.81 \\
9 \# coal seam & 1450 & 4.91 & 2.01 & 1.20 & 32 & 0.58 \\
Mudstone & 2460 & 5.12 & 4.73 & 1.25 & 32 & 0.15 \\
Fine sandstone & 2870 & 21.04 & 13.52 & 3.75 & 32 & 0.58 \\
\hline
\end{tabular}

\subsection{Simulation Scheme}

According to the actual working conditions, the corresponding simulation scheme was formulated. The geometry and boundary conditions of the model are shown in Figures 7 and 8 respectively. The model was fixed around to limit the horizontal movement, and fixed at the bottom to limit the vertical movement, and $5 \mathrm{MPa}$ uniform load was applied at the top to simulate the self-weight boundary of the overlying strata. The mining scheme of coal seam was as follows. For the large pillar mining, (a) the 8102 working face was firstly mined step by step, the excavation footage of each step was set as $10 \mathrm{~m}$. After each step was balanced, the next step of excavation was calculated to balance, and the calculation was carried out step by step. (b) Three mining roadways of 9101 and 9102 working faces were excavated at one time, and a pillar with a width of $15 \mathrm{~m}$ was set, and the calculation was made to the model balance. (c) The 9101 working face was excavated step by step, and the excavation footage was set as $10 \mathrm{~m}$. The mining direction was perpendicular to that of the 8102 working face. For the small pillar mining, (a) ditto; (b) three mining roadways of the 9101 and 9102 working faces were excavated at one time, a pillar with a width of $5 \mathrm{~m}$ was set, and the calculation was made to the model balance; (c) ditto. For the non-pillar mining, (a) ditto; (b) two mining roadways of the 9101 working face were excavated at one time, and the calculation was made to the model balance; (c) pre-cracking roof cutting was conducted firstly. Then the 9101 working face was excavated step by step, and the excavation footage was set to $10 \mathrm{~m}$. The mining direction was perpendicular to that of the 8102 working face. 

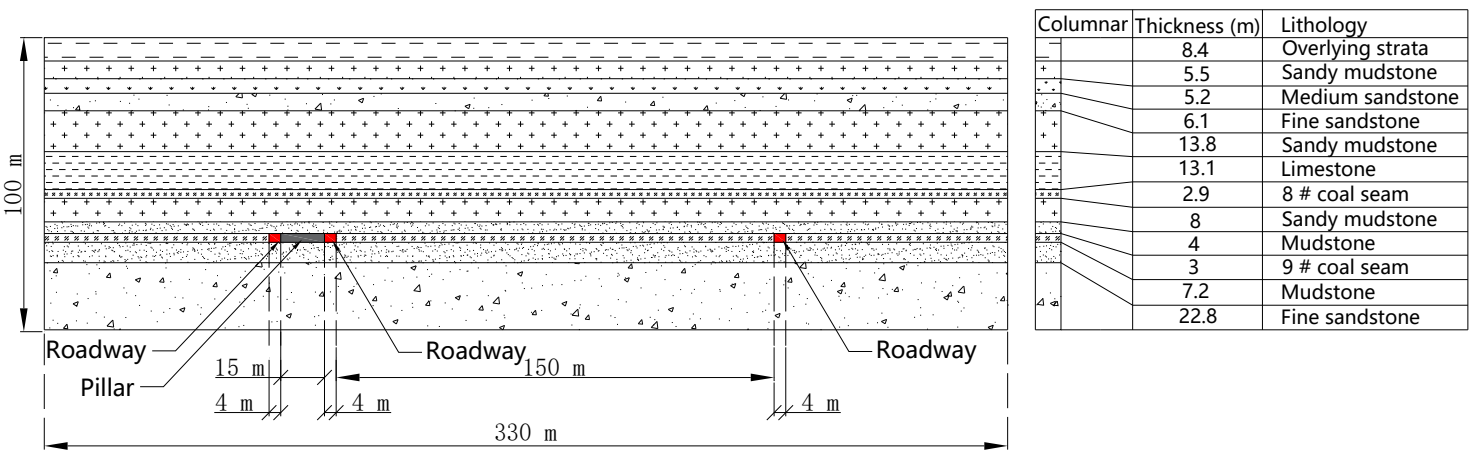

(a)
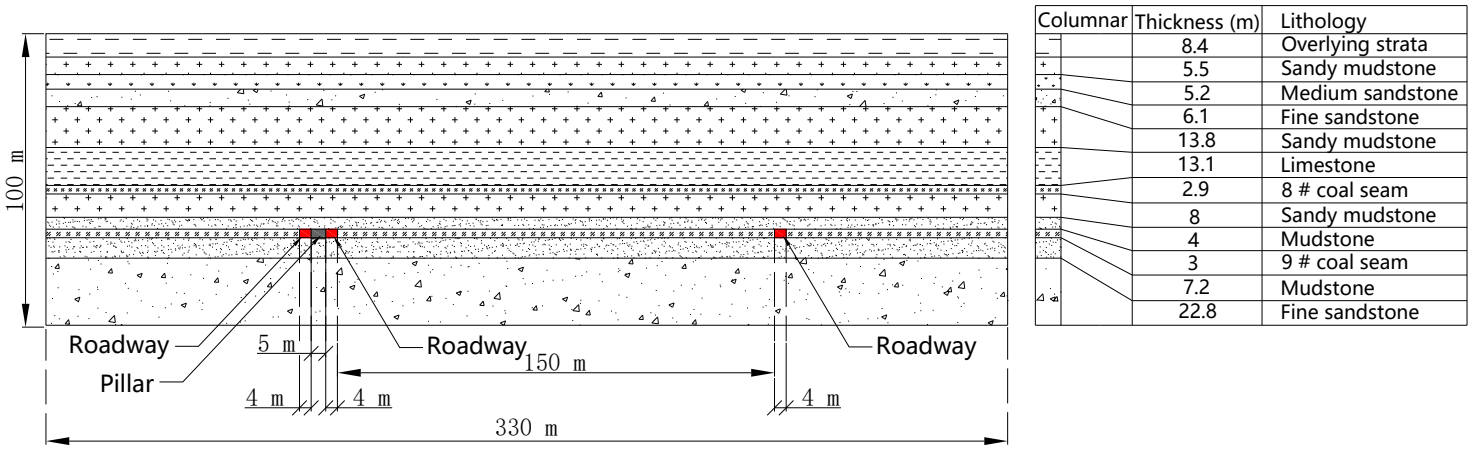

(b)
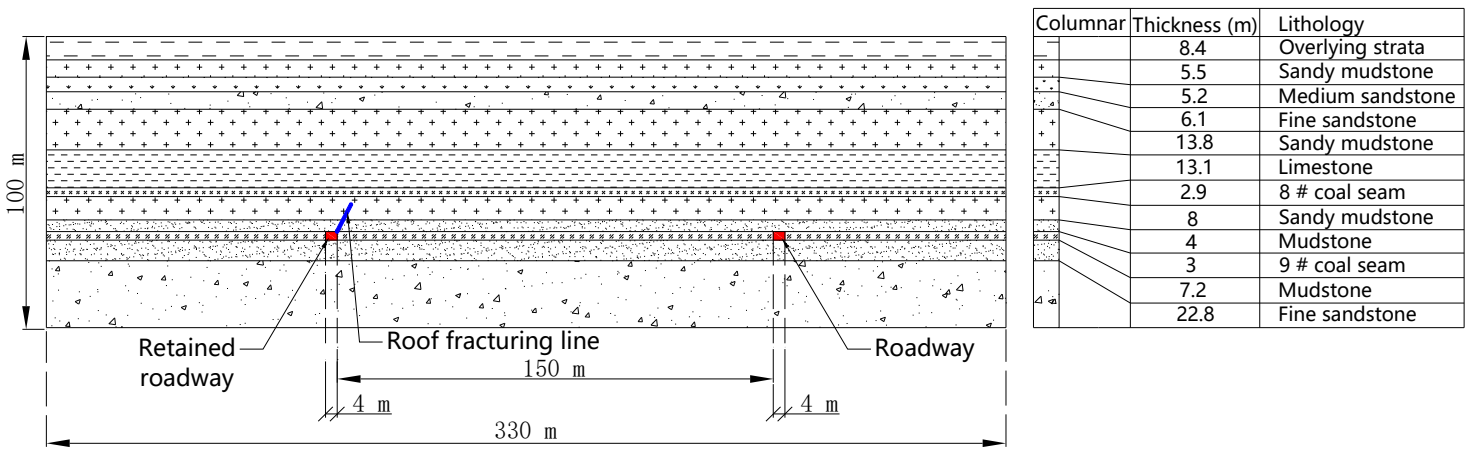

(c)

Figure 7. Geometry of the model. (a) Geometry of model of large pillar mining; (b) geometry of model of small pillar mining; (c) geometry of model of non-pillar mining. 


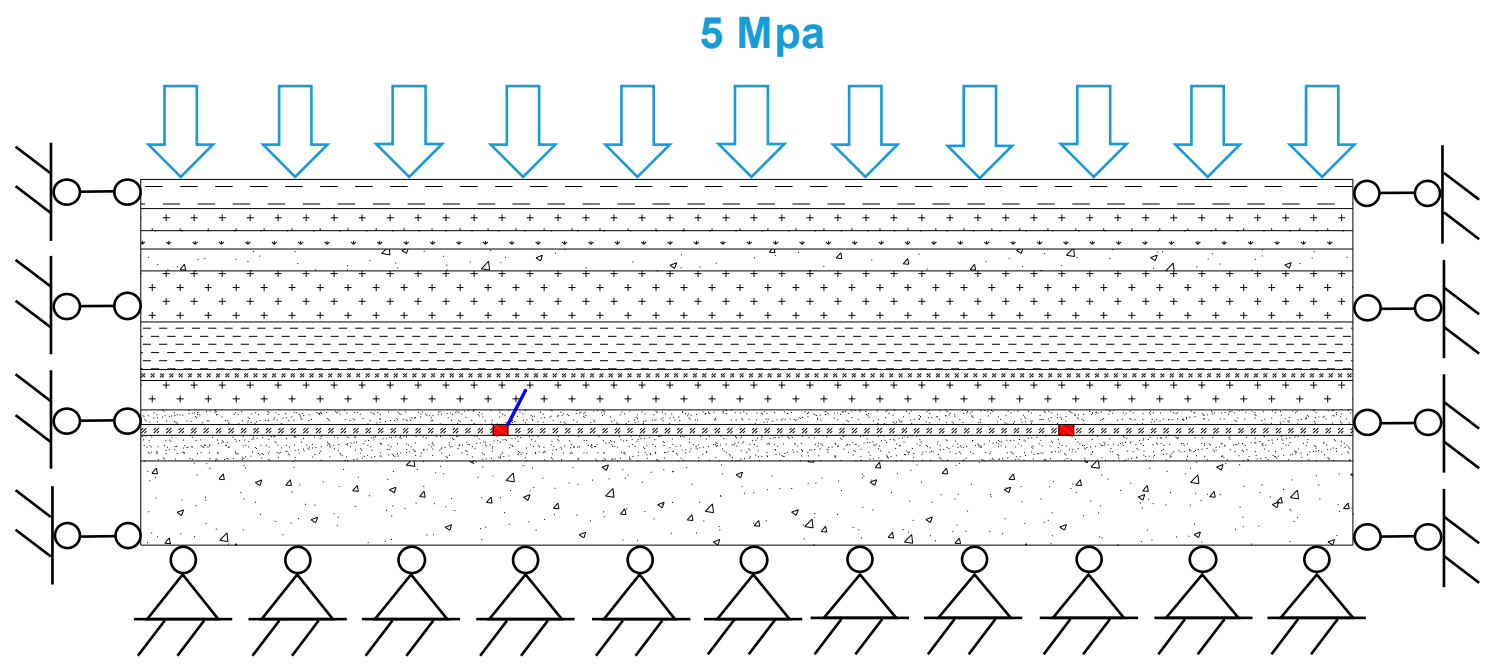

Figure 8. Boundary conditions of the model.

\section{Distribution Law of Three-Dimensional Stress Field}

\subsection{Distribution Law of Vertical Stress}

In order to analyze the evolution law of stress distribution in the surrounding rock of stope, when the working face advances to $120 \mathrm{~m}$, monitoring lines are arranged at different positions of the model, and vertical stress is monitored by monitoring lines. The location of monitoring lines is shown in Figure 9. Among them, one, two and three monitoring lines are located in the inner $10 \mathrm{~m}$ of the 9101 ventilation roadway, the middle of the 9101 working face, and the inner $10 \mathrm{~m}$ of the 9101 haulage roadway; four, five and six monitoring lines are located $5 \mathrm{~m}, 10 \mathrm{~m}$ and $20 \mathrm{~m}$ in front of the working face, respectively; seven, eight and nine monitoring lines are located on the left side of the working face, $5 \mathrm{~m}$, $10 \mathrm{~m}$ and $15 \mathrm{~m}$ in front of the working face respectively; 10, 11, 12 and 13 monitoring lines are located on the left side of working the face, $5 \mathrm{~m}, 10 \mathrm{~m}, 30 \mathrm{~m}$, and $80 \mathrm{~m}$ behind the working face, respectively.
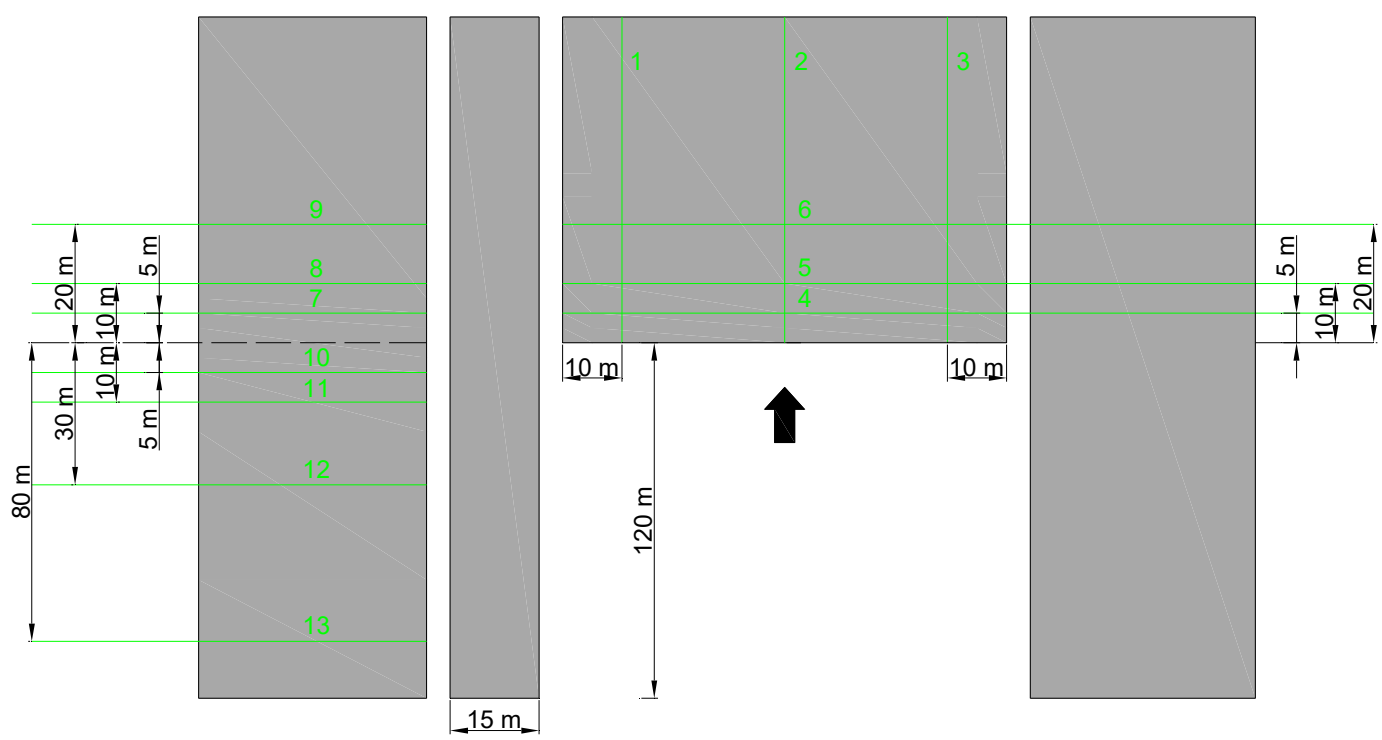

(a)

Figure 9. Cont. 

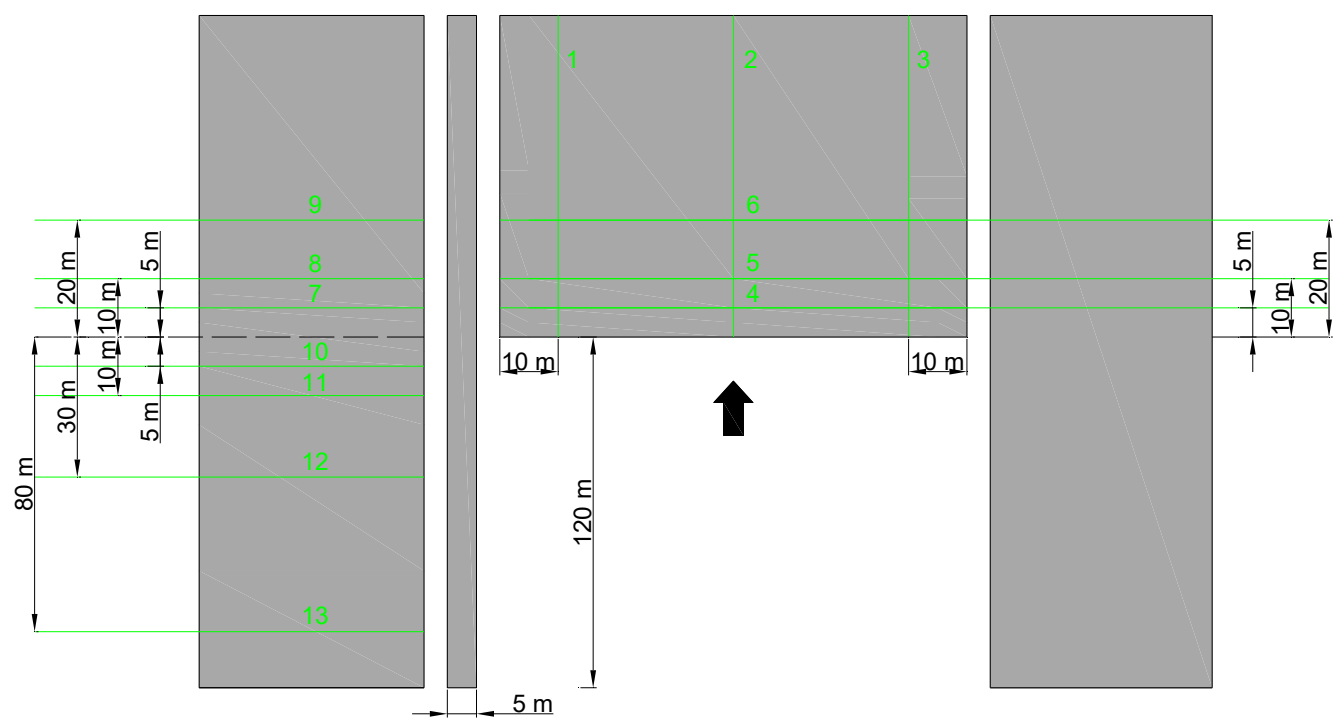

(b)
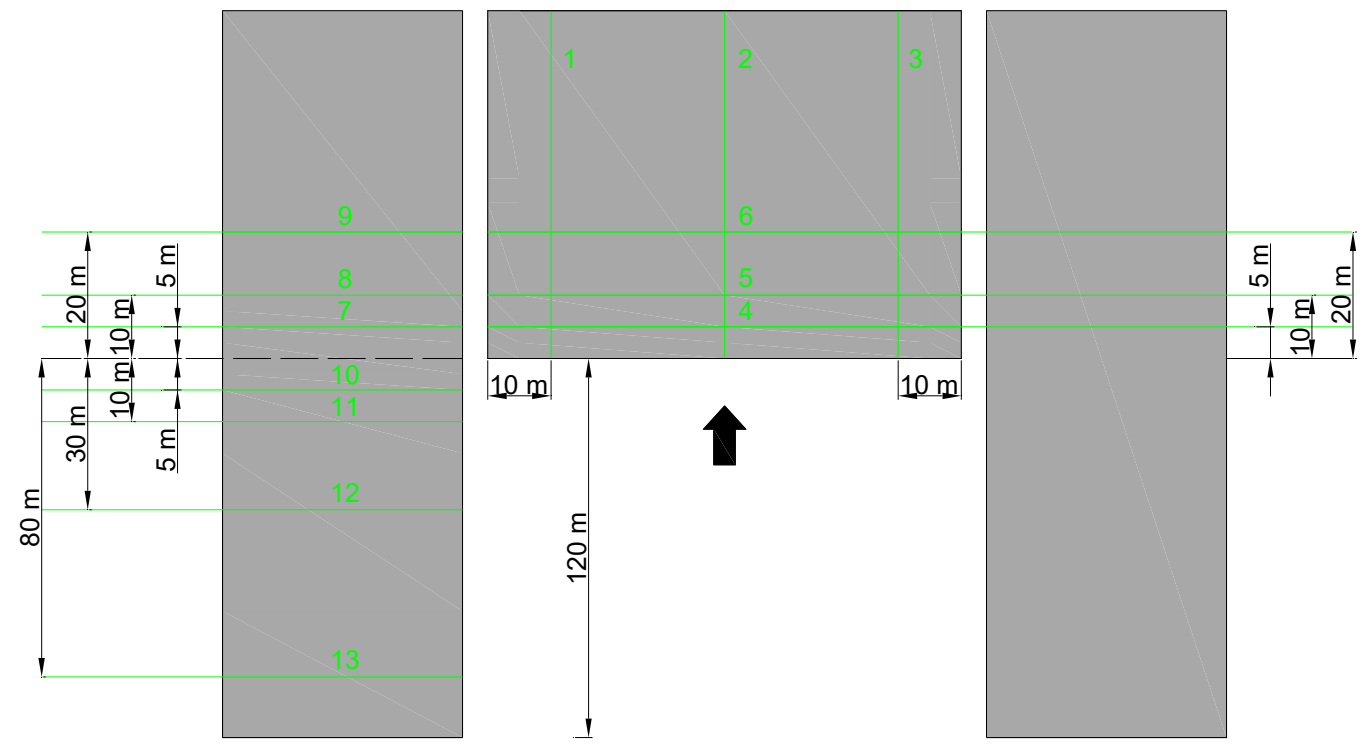

(c)

Figure 9. Location of monitoring lines. (a) Location of monitoring lines of large pillar mining; (b) Location of monitoring lines of small pillar mining; (c) Location of monitoring lines of non-pillar mining.

\subsubsection{Stress Distribution in Front of Working Face}

(1) Stress distribution along working face strike

The vertical stress distribution nephograms and stress distribution curves at monitoring line 1 are shown in Figure 10. Figure 10 shows that the vertical stress distribution along the working face strike was similar under the three mining methods, and the advanced mining stress concentration area of the remaining pillars mining was larger than that of non-pillar mining, and the stress value was slightly higher. The peak of advanced mining stress was located $10 \mathrm{~m}$ in front of the working face, which was about 3.3 times that of the mining height of the working face. Among them, the peak stress of non-pillar mining was $14 \%$ lower than that of large pillar mining and $10 \%$ lower than that of small pillar mining. Within $3 \mathrm{~m}$ from the face, was the pressure-released zone of the stope; the vertical stress value was lower than the original rock stress, and the coal body mainly underwent 
plastic deformation. Under the coupling effect of the overlying goaf and mining abutment pressure of this coal seam, a pressure boost belt was formed within the range of 3-33 $\mathrm{m}$ from the working face. The elastic deformation of coal body in this area caused the accumulation of elastic deformation energy, and the bearing capacity was higher. Within the range of 33-90 m from the working face, under the influence of pressure relief in the goaf of 8 \# coal seam, the stress value was low. From 90-110 $\mathrm{m}$ away from working face, the residual pillar of 8 \# coal seam formed a stress concentration zone here, and the stress value rose again. The stress distribution law at monitoring lines 2 and 3 was similar to that at monitoring line 1 . The peak of advance mining stress was $10 \mathrm{~m}$ ahead of the working face. The peak stress of non-pillar mining was $23.88 \mathrm{MPa}$ and $19.92 \mathrm{MPa}$ respectively, which were $8 \%, 7 \%$ and $-1 \%$, $1 \%$ lower than that of traditional mining respectively (as shown in Table 3 ).

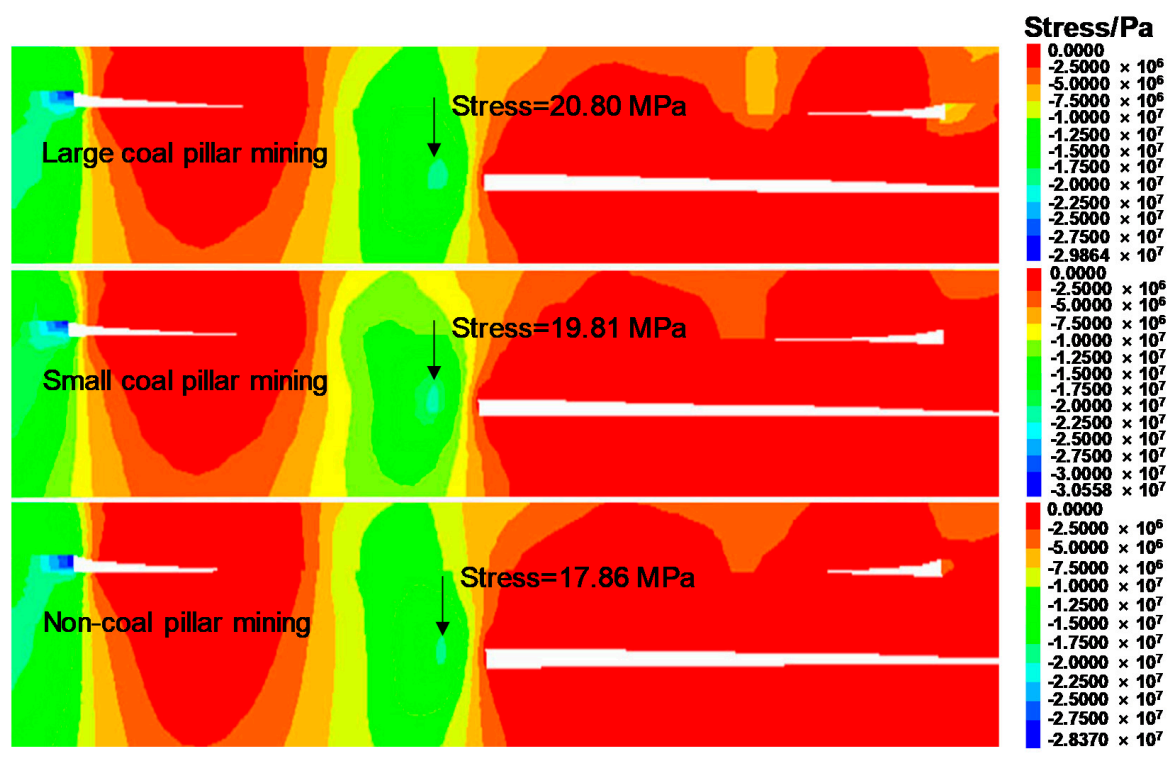

(a)

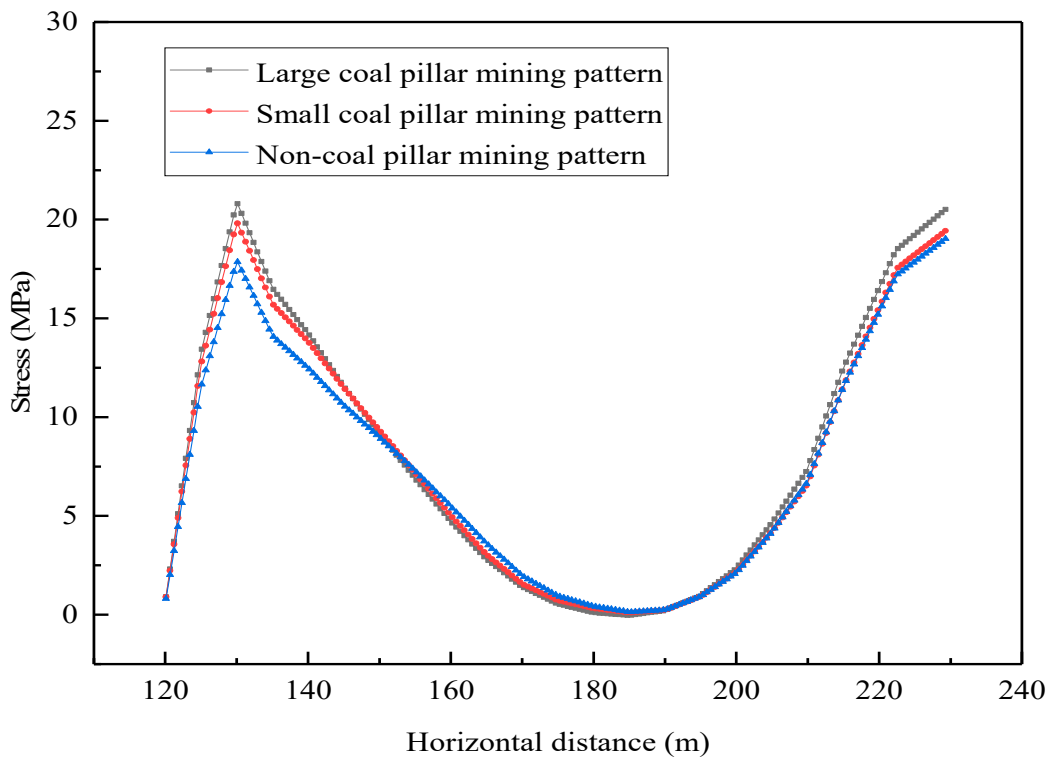

(b)

Figure 10. Vertical stress nephogram and stress distribution curve at the monitoring line 1 along the working face strike. (a) Vertical stress nephogram; (b) Stress distribution curve. 
Table 3. Key parameters of the stress distribution characteristics along the working face strike.

\begin{tabular}{|c|c|c|c|c|c|}
\hline $\begin{array}{l}\text { Monitoring } \\
\text { Line }\end{array}$ & Mining Mode & $\begin{array}{l}\text { Stress } \\
\text { Trend }\end{array}$ & $\begin{array}{l}\text { Peak Position } \\
\text { (m) }\end{array}$ & $\begin{array}{l}\text { Peak Size } \\
\text { (MPa) }\end{array}$ & $\begin{array}{l}\text { Peak Reduction of } \\
(\%)\end{array}$ \\
\hline \multirow{3}{*}{1} & Large & \multirow{3}{*}{ Similar } & 10 & 20.80 & 14 \\
\hline & Small & & 10 & 19.81 & 10 \\
\hline & GERRCP & & 10 & 17.86 & Reference quantity \\
\hline \multirow{3}{*}{2} & Large & \multirow{3}{*}{ Similar } & 10 & 26.05 & 8 \\
\hline & Small & & 10 & 25.63 & 7 \\
\hline & GERRCP & & 10 & 23.88 & Reference quantity \\
\hline \multirow{3}{*}{3} & Large & \multirow{3}{*}{ Similar } & 10 & 19.64 & -1 \\
\hline & Small & & 10 & 20.05 & 1 \\
\hline & GERRCP & & 10 & 19.92 & Reference quantity \\
\hline
\end{tabular}

Based on the above analysis, the key parameters of the stress distribution characteristics along the working face strike in the simulation results were summarized, and a matrix-type chart with resulting values and illustrations was made, so they can be visualized and compared in a single view (as shown in Table 3).

(2) Stress distribution along the inclination of working face

The vertical stress distribution nephograms and stress distribution curves at monitoring line 4 are shown in Figure 11. Figure 11 showed that, the distribution law of vertical stress along the inclination of the working face was similar under the three mining modes, that was, the stress data showed that the vertical stress increased first and then decreased. The stress curves of large and small pillars basically coincided, and the stress value was slightly higher than that of the non-pillar mining method. At the edge of the ventilation roadway, the three stresses were $10.8 \mathrm{MPa}, 10.2 \mathrm{MPa}$ and 7.6 $\mathrm{MPa}$, respectively. The stress of non-pillar mining at the edge of the ventilation roadway was $30 \%$ and $25 \%$ lower than that of the large pillar and small pillar, respectively. At the distance of $10 \mathrm{~m}$ from the ventilation roadway, the three stresses reached $12.8 \mathrm{MPa}, 12.3 \mathrm{MPa}$ and $11.1 \mathrm{MPa}$. The stress of the non-coal pillar mining was $13 \%$ and $10 \%$ lower than that of the large pillar and small pillar mining, respectively. It could be seen that within the distance of $10 \mathrm{~m}$ from the ventilation roadway, the vertical stress increased greatly, while the non-coal pillar mining showed the characteristics of low stress compared with the traditional mining method. The main reason was that the roof rock beam was cut off by pre-cracking the roof cutting, which transformed it from a long-wall beam to short-wall beam and cut off the stress transfer between roofs, which improved the stress condition of surrounding rock obviously. The stress distribution law at monitoring lines 5 and 6 was similar to that at monitoring line 4 . The stress increased rapidly within $10 \mathrm{~m}$ from the ventilation roadway and then slowed down. The stress distribution of traditional mining was axisymmetrical about the middle of the working face, while the stress of the side of the roof cutting of non-pillar mining was significantly lower than that of the non-roof cutting. Among them, the peak stress of non-pillar mining was $23.98 \mathrm{MPa}$ and $19.41 \mathrm{MPa}$ respectively, which were $7 \%, 7 \%$ and $10 \%, 8 \%$ lower than that of traditional mining respectively (as shown in Table 4). 


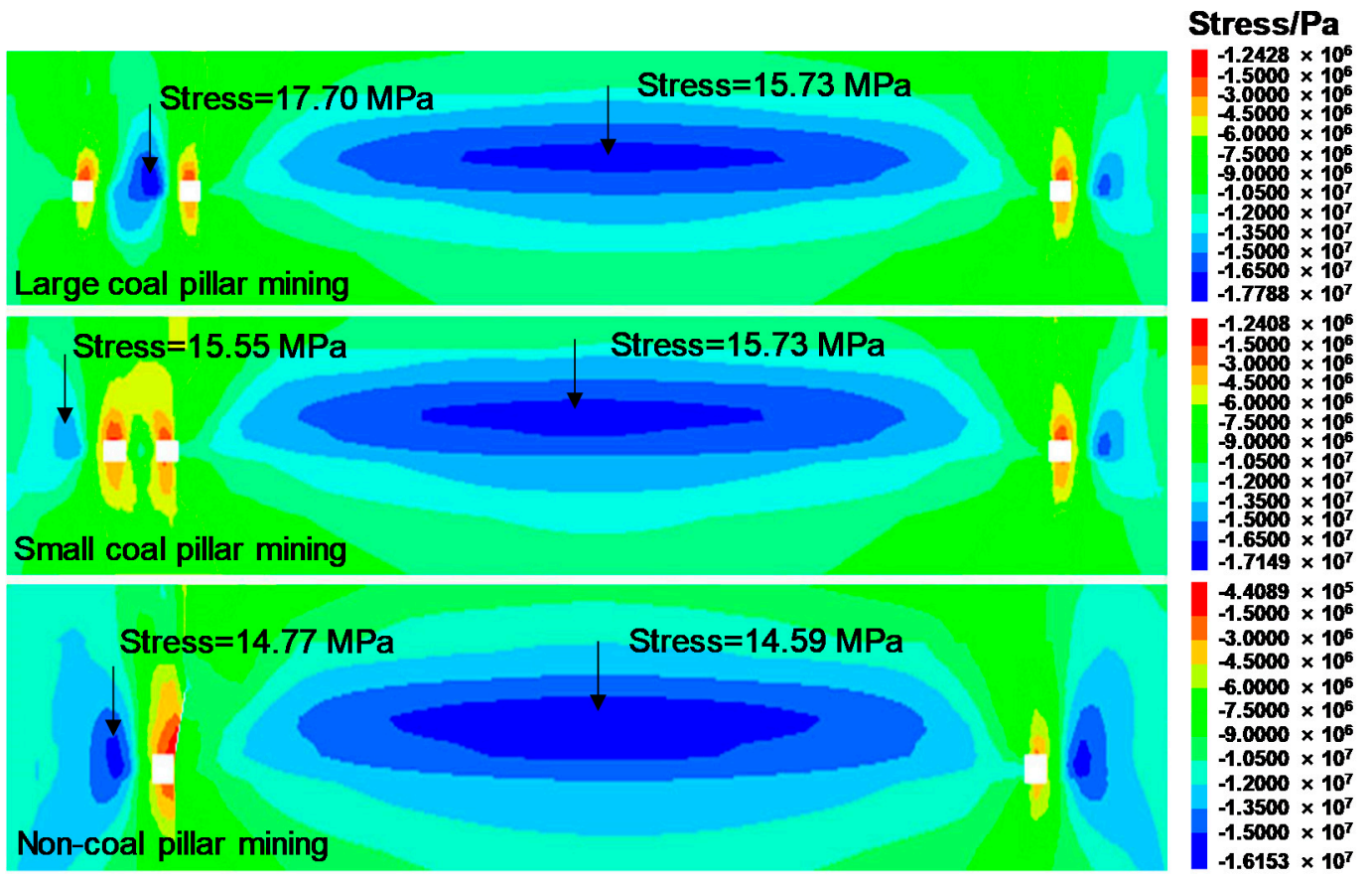

(a)

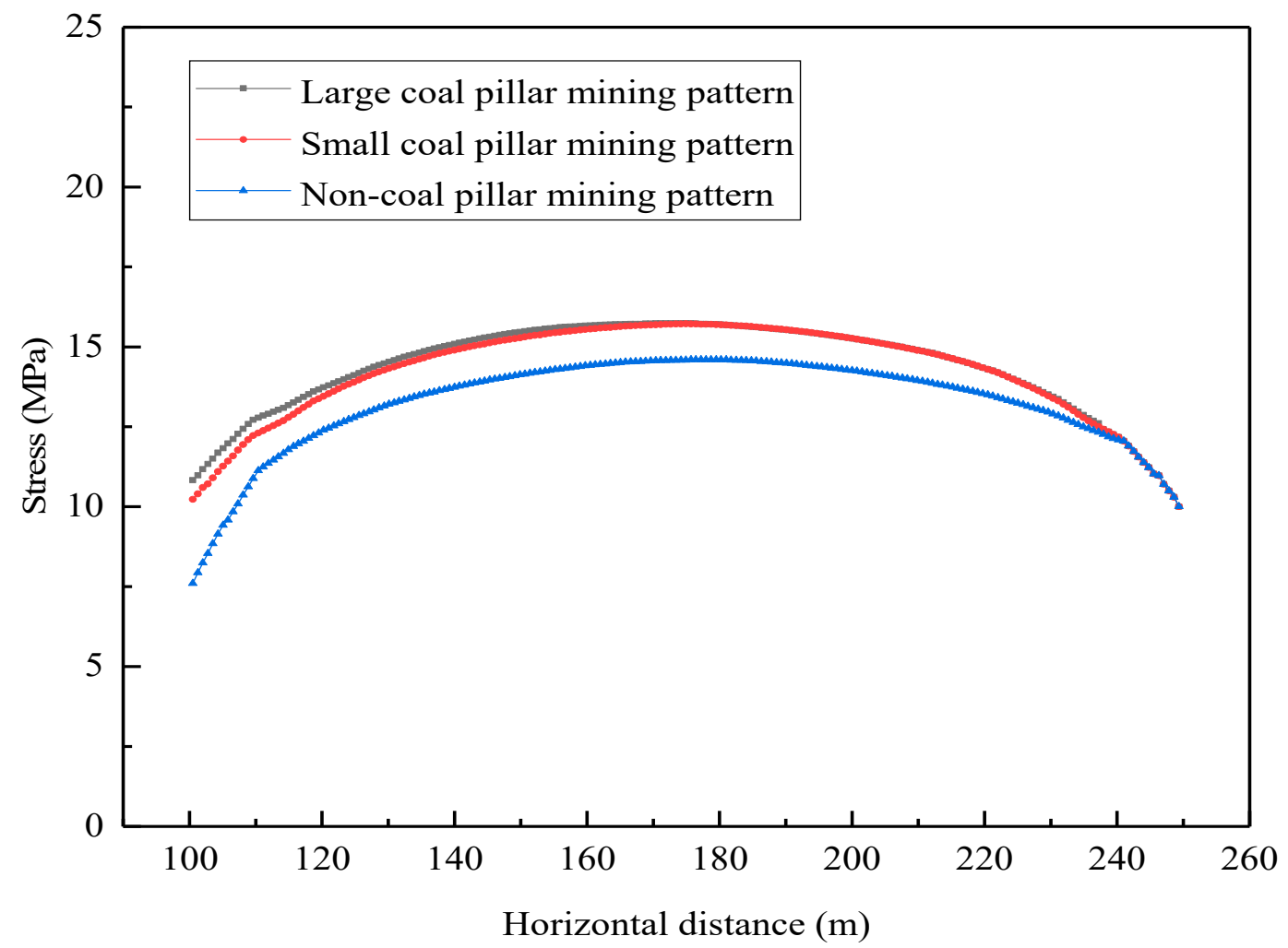

(b)

Figure 11. Vertical stress nephogram and stress distribution curve at the monitoring line 4 along the inclination of the working face. (a) Vertical stress nephogram; (b) Vertical stress distribution curve. 
Table 4. Key parameters of the stress distribution characteristics along the inclination of the working face.

\begin{tabular}{cccccc}
\hline $\begin{array}{c}\text { Monitoring } \\
\text { Line }\end{array}$ & $\begin{array}{c}\text { Mining } \\
\text { Mode }\end{array}$ & $\begin{array}{c}\text { Stress } \\
\text { Concentration } \\
\text { around Roadway } \\
\mathbf{( M P a )}\end{array}$ & $\begin{array}{c}\text { Peak } \\
\text { Reduction (\%) }\end{array}$ & $\begin{array}{c}\text { Stress } \\
\text { Concentration } \\
\text { of Working } \\
\text { Face (MPa) }\end{array}$ & $\begin{array}{c}\text { Peak } \\
\text { Reduction (\%) }\end{array}$ \\
\hline \multirow{2}{*}{4} & Large & 17.70 & 17 & 15.73 & 7 \\
\cline { 2 - 6 } & Small & 15.55 & 5 & 15.73 & 7 \\
\cline { 2 - 6 } & GERRCP & 14.77 & $\begin{array}{c}\text { Reference } \\
\text { quantity }\end{array}$ & 14.59 & $\begin{array}{c}\text { Reference } \\
\text { quantity }\end{array}$ \\
\cline { 2 - 6 } & Large & 15.34 & 12 & 25.87 & 7 \\
\hline & GERRCP & 14.60 & 8 & 25.79 & $\begin{array}{c}\text { Reference } \\
\text { quantity }\end{array}$ \\
\hline & Large & 14.45 & 13 & 21.60 & 10 \\
\cline { 2 - 6 } & Small & 13.40 & 7 & 21.18 & 8 \\
\hline
\end{tabular}

Through the above analysis, the key parameters of the stress distribution characteristics along the inclination of the working face were summarized, and a matrix-type chart with resulting values and illustrations was made (as shown in Table 4).

\subsubsection{Stress Distribution in Lateral Direction of Working Face}

(1) Stress distribution in left front of working face

The vertical stress distribution curves at monitoring line 7 are shown in Figure 12. Figure 12 showed that there were two peaks along the working face inclination under the condition of large and small pillars mining. The locations of peak stress were $6 \mathrm{~m}, 23 \mathrm{~m}$ and $2 \mathrm{~m}, 15 \mathrm{~m}$ away from the edge of ventilation roadway respectively, with sizes of $17.7 \mathrm{MPa}, 12.3 \mathrm{MPa}$ and $10.8 \mathrm{MPa}, 15.6 \mathrm{MPa}$. The stress concentration factors were 2.6, 1.8 and 1.6, 2.3. There was a wave peak along the inclination of the working face under non-pillar mining, which was located $5 \mathrm{~m}$ outside ventilation roadway, with a size of $14.8 \mathrm{MPa}$, and the stress concentration factor was 2.2. Compared with the peak stress, it could be seen that the non-pillar mining decreased by $16 \%$ and $5 \%$ for large and small pillar mining respectively, indicating that the non-pillar mining had less influence on the advanced mining stress of the roadway surrounding rock, that was, the technology of roof cutting and pressure relief cut off the stress transfer between the working face and roadway roof, and the stress control effect was better. By analyzing the location of peak stress, it could be seen that the peak stress of the retaining pillar mining mode was $6 \mathrm{~m}$ outside the roadway, while that of the non-pillar mining mode was $5 \mathrm{~m}$ outside the roadway, which indicated that the plastic zone of surrounding rock in the advanced position of a roadway under non-pillar mining mode was smaller. In addition, the advantages of this mining method on the stress control of surrounding rock were further reflected. The stress distribution law at monitoring lines 8 and 9 was similar to that at monitoring line 7 . The advance abutment pressure in lateral direction of the working face was lower than that of monitoring line 7 . The peak stress of traditional mining was $6 \mathrm{~m}$ outside the ventilation roadway, while the peak stress of non-pillar mining was $5 \mathrm{~m}$ from the ventilation roadway. The peak stresses of non-pillar mining were $13.5 \mathrm{MPa}$ and 12.5 MPa respectively, which were $12 \%, 8 \%$ and $13 \%, 7 \%$ lower than that of traditional mining respectively (as shown in Table 5). 


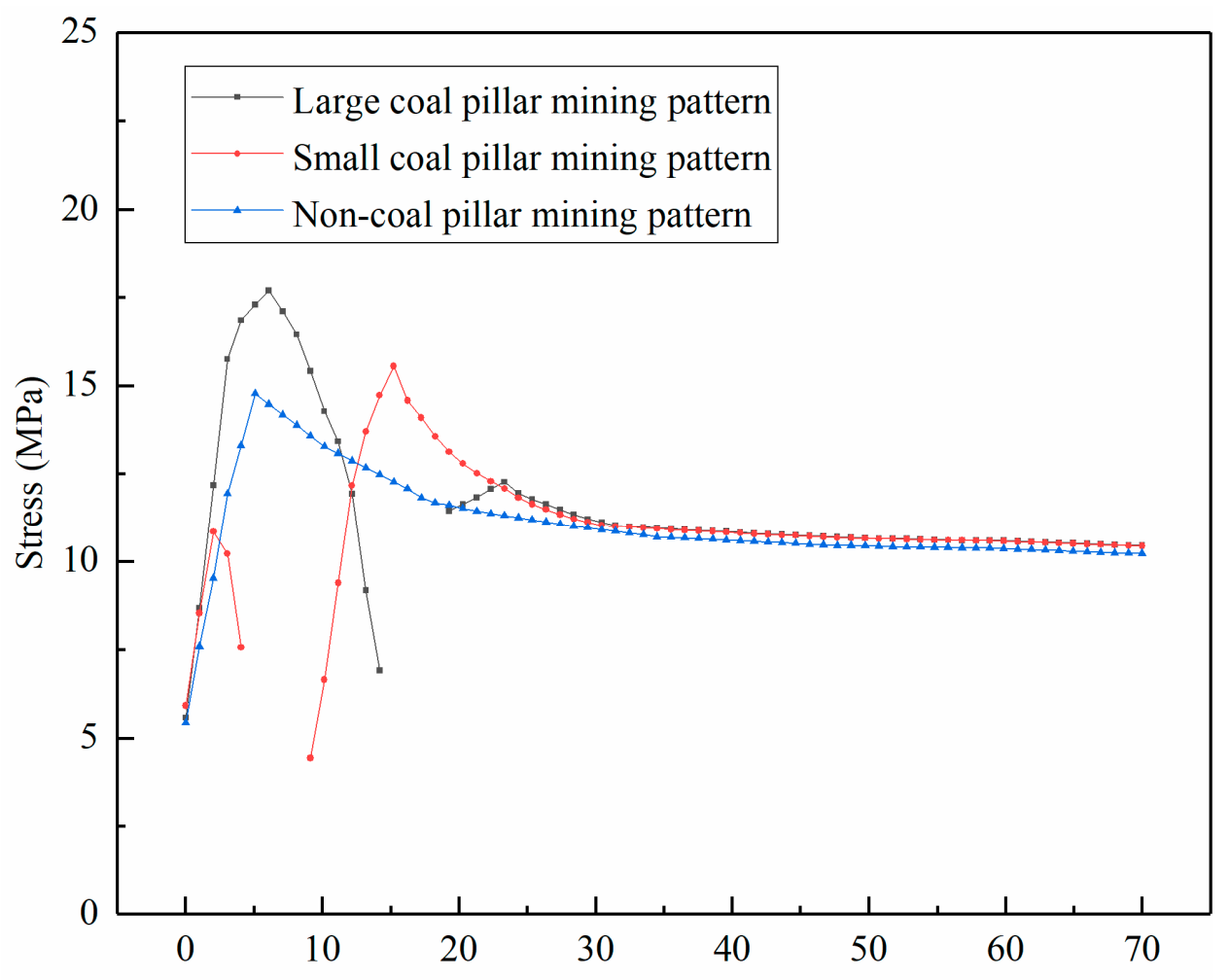

Distance from roadway edge (m)

Figure 12. Vertical stress distribution curve at monitoring line 7 in lateral direction of the working face.

Table 5. Key parameters of the stress distribution characteristics in the left front of the working face.

\begin{tabular}{|c|c|c|c|c|c|}
\hline $\begin{array}{l}\text { Monitoring } \\
\text { Line }\end{array}$ & $\begin{array}{l}\text { Mining } \\
\text { Mode }\end{array}$ & $\begin{array}{c}\text { Number of } \\
\text { Peaks }\end{array}$ & $\begin{array}{c}\text { Peak Position } \\
\text { (m) }\end{array}$ & $\begin{array}{l}\text { Peak Size } \\
\text { (MPa) }\end{array}$ & $\begin{array}{c}\text { Peak } \\
\text { Reduction (\%) }\end{array}$ \\
\hline \multirow{3}{*}{7} & Large & 2 & 6 & 17.7 & 16 \\
\hline & Small & 2 & 6 & 15.6 & 5 \\
\hline & GERRCP & 1 & 5 & 14.8 & $\begin{array}{l}\text { Reference } \\
\text { quantity }\end{array}$ \\
\hline \multirow{3}{*}{8} & Large & 2 & 6 & 15.3 & 12 \\
\hline & Small & 2 & 6 & 14.6 & 8 \\
\hline & GERRCP & 1 & 5 & 13.5 & $\begin{array}{l}\text { Reference } \\
\text { quantity }\end{array}$ \\
\hline \multirow{3}{*}{9} & Large & 2 & 6 & 14.4 & 13 \\
\hline & Small & 2 & 6 & 13.4 & 7 \\
\hline & GERRCP & 1 & 5 & 12.5 & $\begin{array}{l}\text { Reference } \\
\text { quantity }\end{array}$ \\
\hline
\end{tabular}

Combined with the analysis results, the key parameters of the stress distribution characteristics in the left front of the working face in the simulation results were summarized, and a matrix-type chart with resulting values and illustrations was made (as shown in Table 5).

(2) Stress distribution in left rear of working face

The vertical stress distribution curves at monitoring line 10 are shown in Figure 13. Figure 13 showed that, there were obvious differences in the stress distribution characteristics along the inclination of the working face under the three mining methods, which were mainly reflected in 
the stress concentration area and the degree of stress concentration. Figure 13b intuitively showed that, in the lateral direction of the working face, the stress of the large pillar mining method was the largest, followed by the small pillar mining and the minimum of the non-pillar mining method. Under the traditional mining method, the vertical stress showed that the distribution characteristics were saddle-shaped, in which the large pillar mining first formed the stress concentration in the large pillar, that was, the first wave peak appeared. Then a small degree of concentration appeared at the roadway edge of the 9102 working face, forming a second wave peak, indicating that the stope underground pressure was mainly borne by the large pillar behind the working face. The small pillar mining was obviously different from large pillar mining. The larger stress concentration was located at the 9102 working face, and a smaller concentration occurred in the small pillar, indicating that the small pillar had a low bearing capacity behind the working face due to the limitation of coal pillar width, and the stress bearing area transferred to the deep part of the working face. Because of the elimination of pillars for the non-pillar mining method, the weight of overlying strata was borne by the solid coal on the working face, and a stress bearing area was formed in the 9102 working face. Therefore, the stress concentration position was transferred from the traditional pillar area to the deep part of the working face, and the peak of non-pillar mining was the smallest, which was $21 \%$ and $10 \%$ lower than the traditional mining method of large pillar and small pillar respectively. It could be seen that the technique of gob-side roof cutting effectively reduced the stress concentration in stope and optimized the stress distribution in the lateral direction of the working face. The stress distribution law at monitoring lines 11,12, and 13 was similar to that at monitoring line 10. Traditional mining methods still showed the characteristics of double-stress wave peak distribution, in which the high stress concentration in large pillar, small pillar and no pillar mining methods occurred in the pillar, 9102 working face and deep part of the solid coal, respectively. The peak stresses were the smallest of non-pillar mining, which were $18 \%, 10 \% ; 16 \%, 6 \%$ and $13 \%, 7 \%$ lower than that of traditional mining respectively (as shown in Table 6).

Table 6. Key parameters of the stress distribution characteristics in the left rear of the working face.

\begin{tabular}{|c|c|c|c|c|c|}
\hline $\begin{array}{l}\text { Monitoring } \\
\text { Line }\end{array}$ & $\begin{array}{l}\text { Mining } \\
\text { Mode }\end{array}$ & $\begin{array}{c}\text { Number of } \\
\text { Peaks }\end{array}$ & $\begin{array}{l}\text { Peak Position } \\
\text { (m) }\end{array}$ & $\begin{array}{l}\text { Peak Size } \\
\text { (MPa) }\end{array}$ & $\begin{array}{c}\text { Peak } \\
\text { Reduction (\%) }\end{array}$ \\
\hline \multirow{3}{*}{10} & Large & 2 & 6 & 21.52 & 21 \\
\hline & Small & 2 & 6 & 18.80 & 10 \\
\hline & GERRCP & 1 & 5 & 16.99 & $\begin{array}{l}\text { Reference } \\
\text { quantity }\end{array}$ \\
\hline \multirow{3}{*}{11} & Large & 2 & 6 & 21.68 & 18 \\
\hline & Small & 2 & 6 & 19.84 & 10 \\
\hline & GERRCP & 1 & 5 & 17.83 & $\begin{array}{l}\text { Reference } \\
\text { quantity }\end{array}$ \\
\hline \multirow{3}{*}{12} & Large & 2 & 6 & 23.70 & 16 \\
\hline & Small & 2 & 6 & 21.17 & 6 \\
\hline & GERRCP & 1 & 5 & 20.00 & $\begin{array}{l}\text { Reference } \\
\text { quantity }\end{array}$ \\
\hline \multirow{3}{*}{13} & Large & 2 & 6 & 27.17 & 21 \\
\hline & Small & 2 & 6 & 22.16 & 3 \\
\hline & GERRCP & 1 & 5 & 21.58 & $\begin{array}{l}\text { Reference } \\
\text { quantity }\end{array}$ \\
\hline
\end{tabular}




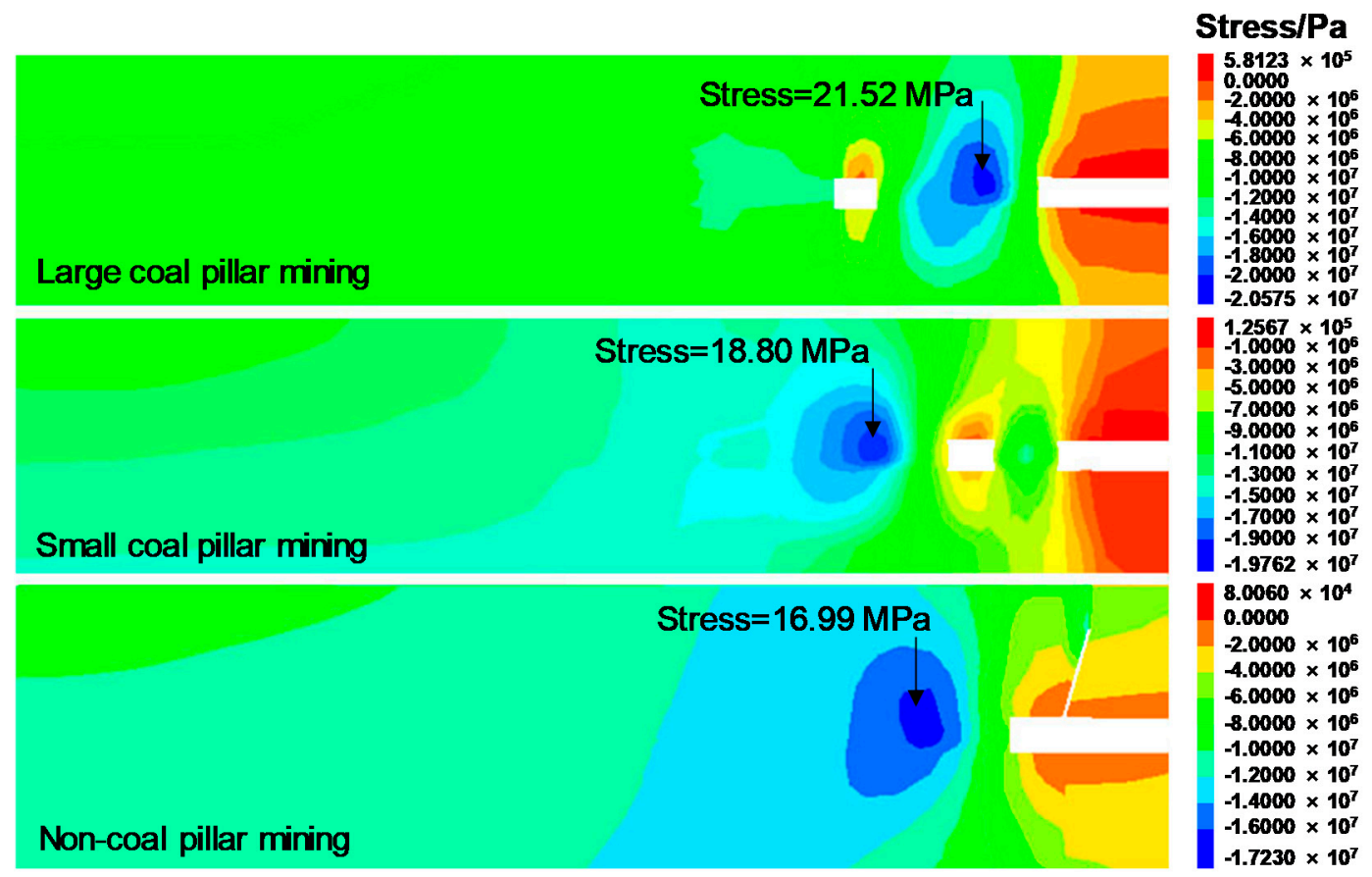

(a)

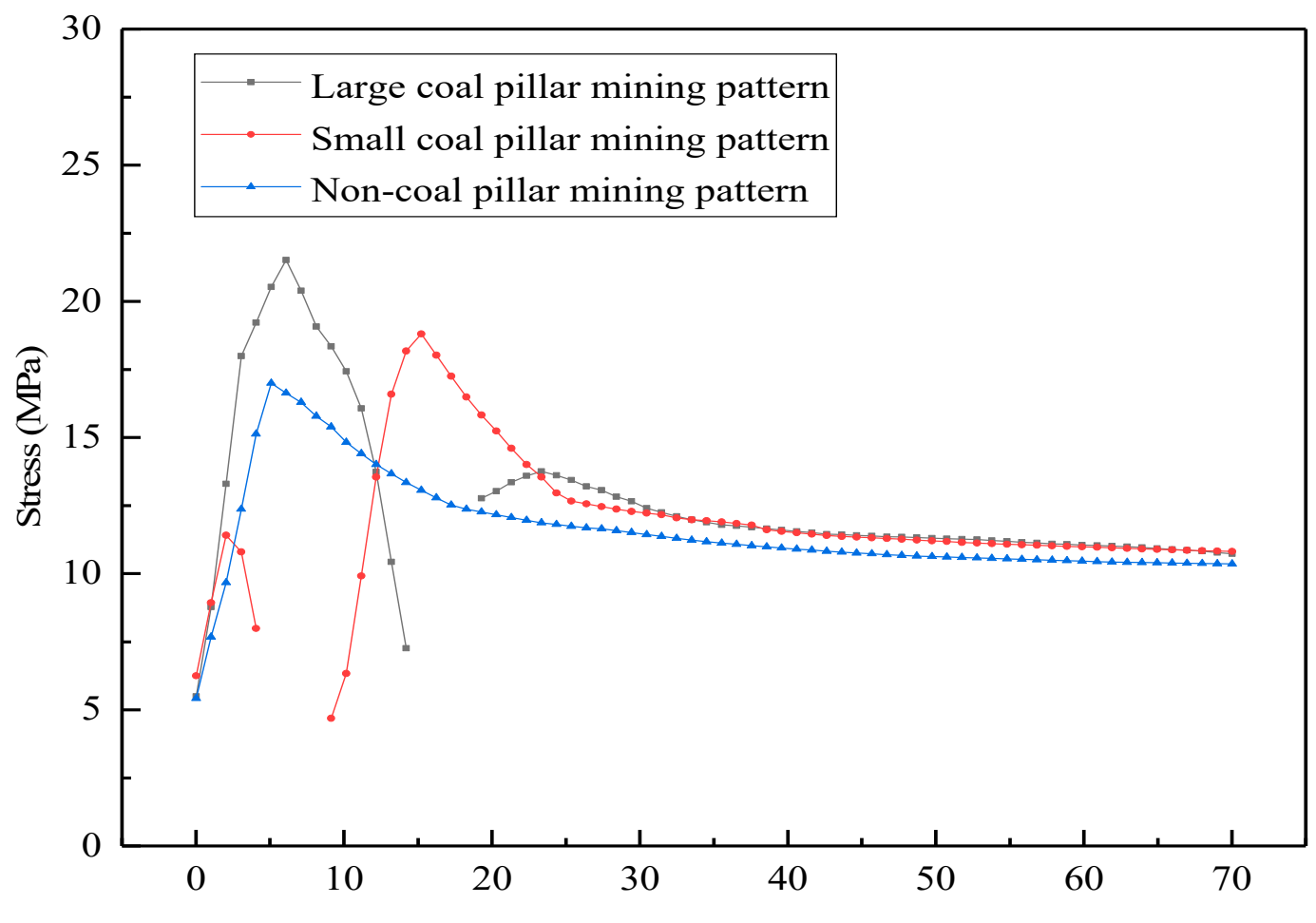

Distance from roadway edge $(\mathrm{m})$

(b)

Figure 13. Vertical stress nephogram and stress distribution curve at monitoring line 10 in lateral direction of working face. (a) Vertical stress nephogram; (b) Vertical stress distribution curve.

With the help of the above analysis, the key parameters of the stress distribution characteristics in the left rear of the working face were summarized, and a matrix-type chart with resulting values and illustrations was made (as shown in Table 6). 


\subsection{Distribution Law of Horizontal Stress}

In order to analyze the distribution of horizontal stress, the model was sliced horizontally. As this study focused on the analysis of the distribution characteristics of the mining stress field in 9 \# coal seam, therefore, in the middle of the height range of the face, horizontal slices were made to analyze the evolution law of horizontal stress in the front and side of the working face.

\subsubsection{Stress Distribution in Front of Working Face}

When the working face advanced to $120 \mathrm{~m}$, the horizontal stress distribution in the front and side of the working face under the three mining modes is shown in Figure 14. In front of the working face, the horizontal stress increased first and then decreased. Under the large pillar mining mode, the stress rising area was large with a span of about $31 \mathrm{~m}$, and the peak stress was $20.5 \mathrm{MPa}$. The peak stress was located $10 \mathrm{~m}$ in front of the working face. Under the small pillar mining mode, the stress rising area was slightly smaller, the span was about $23 \mathrm{~m}$, the peak stress was $16.8 \mathrm{MPa}$, and the stress wave peak was located $10 \mathrm{~m}$ ahead of the working face. The area of stress rise was the smallest under non-pillar mining, with a span of about $9 \mathrm{~m}$, a peak stress of $15.2 \mathrm{MPa}$ and the stress wave peak was located $10 \mathrm{~m}$ ahead of the working face.
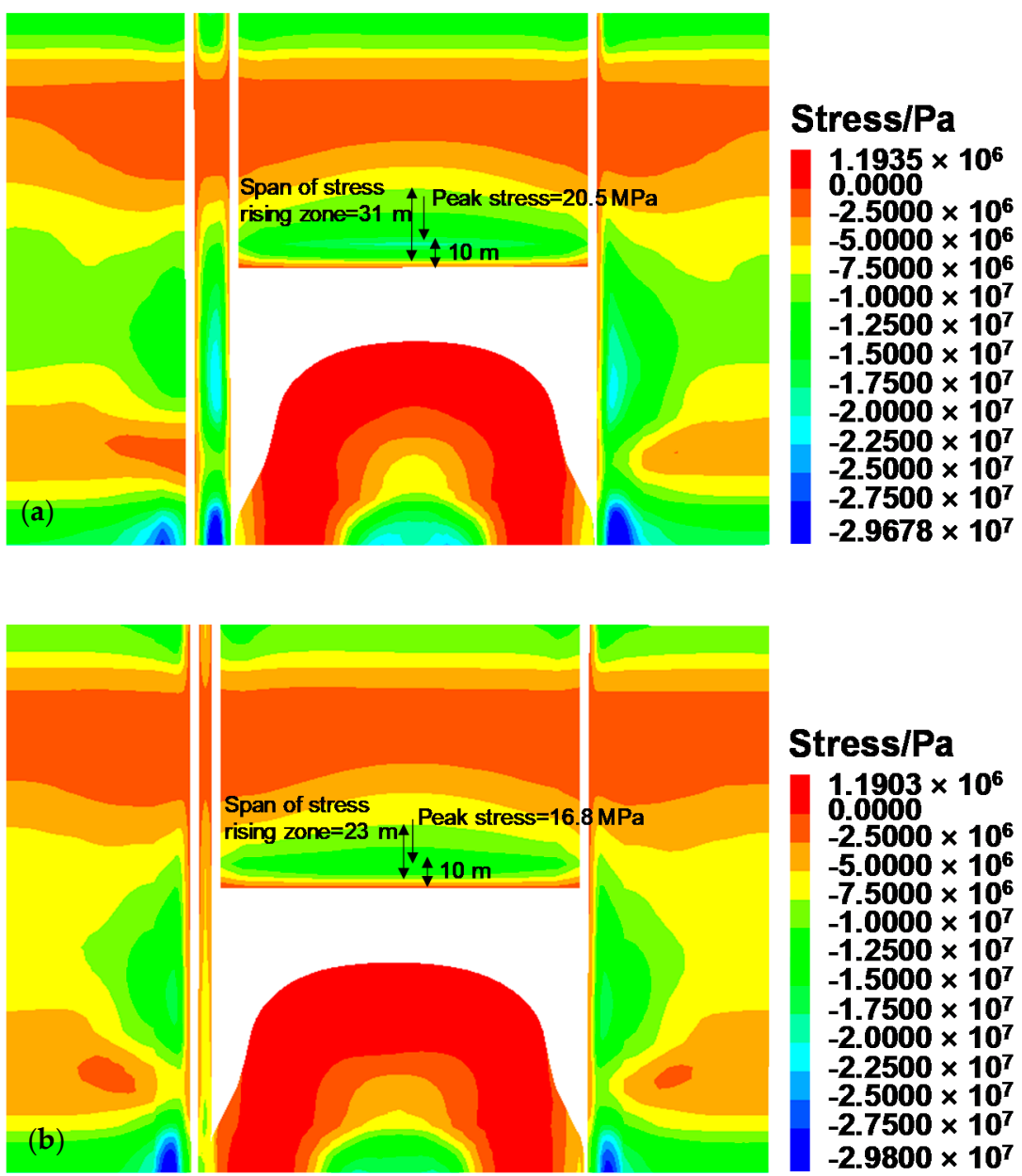

\section{Stress/Pa}

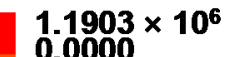

$-2.5000 \times 10^{6}$

$-5.0000 \times 10^{6}$

$-7.5000 \times 10^{6}$

$-1.0000 \times 10^{7}$

$-1.2500 \times 10^{7}$

$-1.5000 \times 10^{7}$

$-1.7500 \times 10^{7}$

$-2.0000 \times 10^{7}$

$-2.2500 \times 10^{7}$

$-2.5000 \times 10^{7}$

$-2.7500 \times 10^{7}$

$-2.9800 \times 10^{7}$

Figure 14. Cont. 


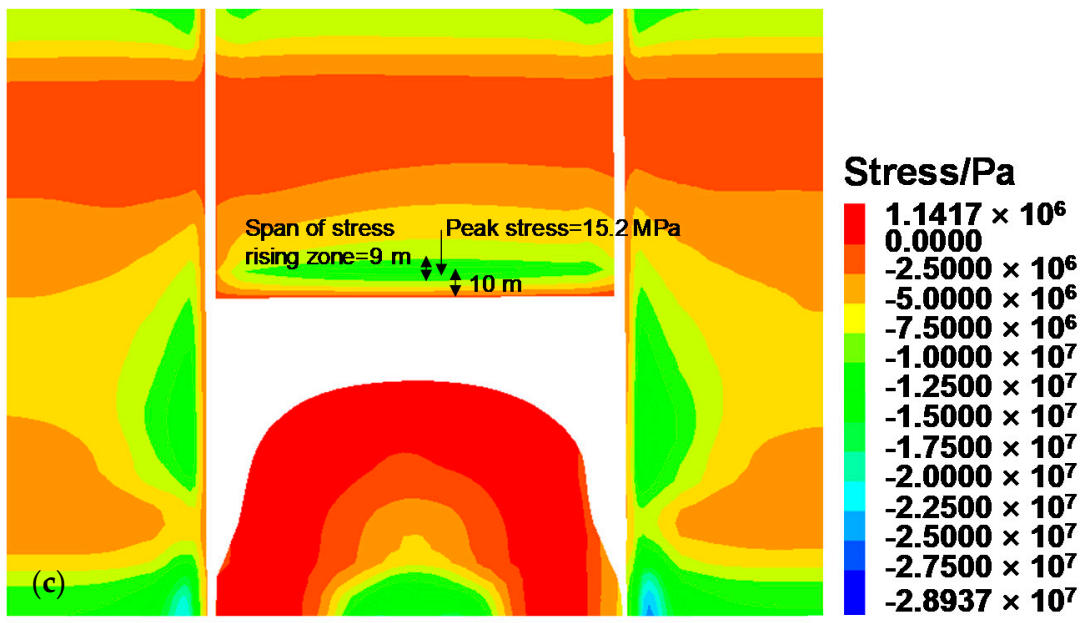

Figure 14. Horizontal stress distribution in front and side of the working face under the three mining modes. (a) Large pillar mining; (b) Small pillar mining; (c) Non-pillar mining.

The stress data showed that the non-pillar mining had the characteristics of a small stress rising area and small stress value. Therefore, it could be concluded that non-pillar mining technology could indeed improve the distribution of the surrounding rock stress field in front of the working face, which was of great significance to reduce the surrounding rock stress in the stope.

\subsubsection{Stress Distribution in Lateral Direction of Working Face}

Figure 14 showed that, in the lateral direction of the working face, high stress concentration was formed in the pillar under large pillar mining, and the stress concentration zone was also formed in the coal body of the 9102 working face; the stress concentration in the pillar under the small pillar mining was not obvious, but the phenomenon of a large stress concentration zone was formed in the 9102 working face; the phenomenon of stress rise occurred in the 9102 working face under non-pillar mining, but the area of the concentrated area was lower than that of the remaining pillars mining mode. This was because the retaining roadway by roof-cutting cut off the stress transfer between the working face and its lateral direction, so the value of the stress in the lateral direction of the working face was reduced and had the characteristics of optimizing the stress distribution in the lateral direction of the working face.

\section{Mine Pressure Monitoring}

\subsection{Stress Monitoring}

In former sections, the distributions of advance stress and lateral abutment pressure in 9101 working face were studied by numerical simulation. On-site measurements of the strike and lateral abutment pressure of 9101 working face were carried out in this section. With the help of monitoring data, the distribution law of mine pressure was analyzed to verify the numerical simulation results.

\subsubsection{Monitoring System}

At present, the KJ550 on-line stress monitoring system was used in Xiashanmao coal mine. The system consists of three main components (as shown in Figure 15): (1) The monitoring host and data processing and analysis system on the ground, adopting a high-performance integrated server workstation and high-performance computer, which can realize the functions of data storage and analysis. (2) The underground monitoring substation (including a power supply), whose main components are industrial high-performance electronic accessories. (3) The pressure sensing system arranged along the entry on both sides of the working face is composed of the borehole stress meter with hydraulic oil as the pressure-sensing medium and high-precision pressure sensors. 


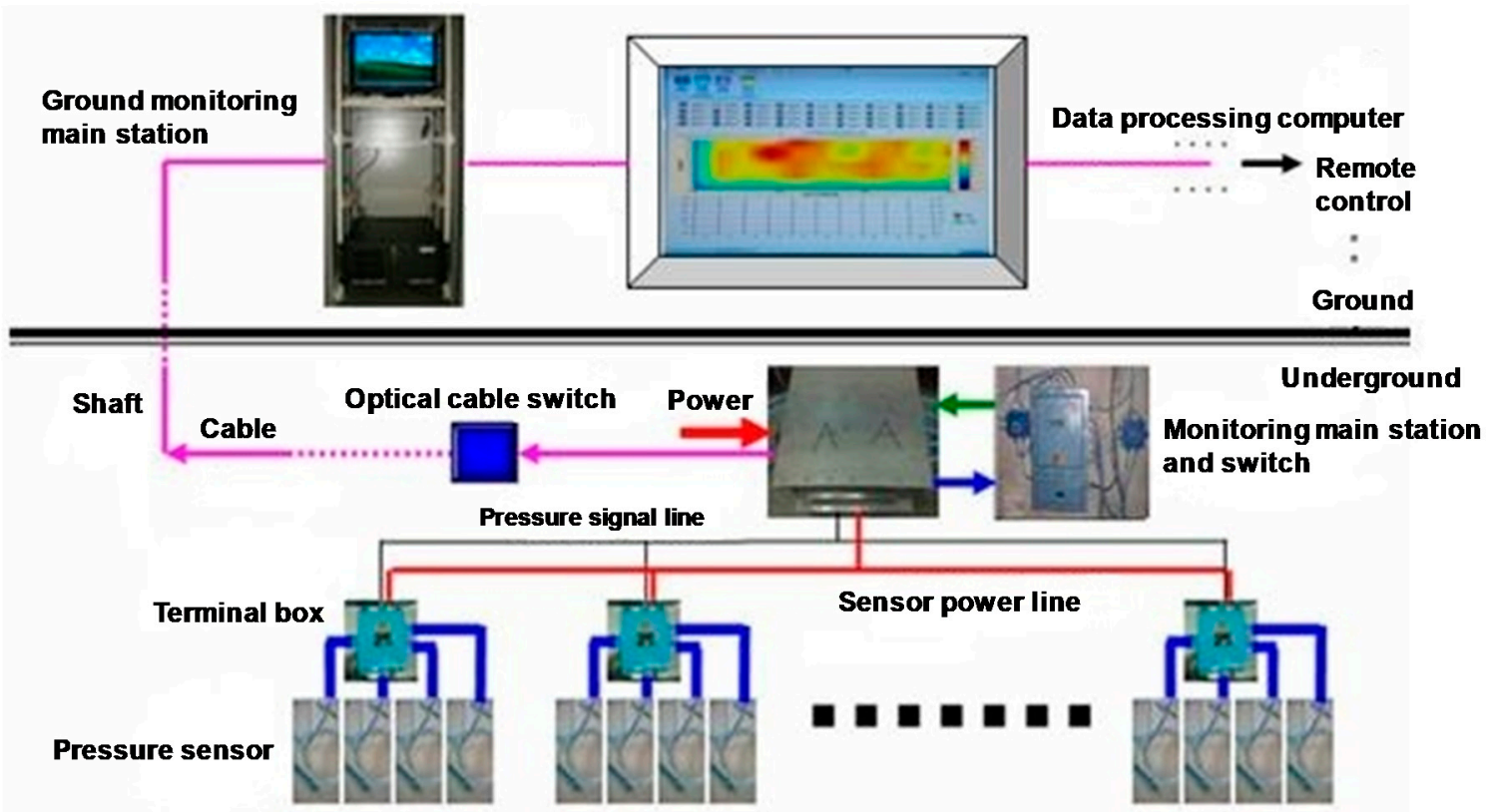

Figure 15. Schematic diagram of remote monitoring system.

The structure and working principle of the system are shown in Figure 15. Under the influence of mining, the pressure of coal and rock mass around the pressure sensor installed in the survey area changes. The sensor receives the pressure fluctuation signal and transmits it to the terminal box, which is transmitted through the pressure signal line to the monitoring main station and switch. The monitoring main station and switch convert the electrical signal into an optical signal, then transmit the optical signal to the ground-monitoring main station through the optical cable switch, and then transmit it to the data-processing computer for stress data processing, so as to realize remote control.

Real-time monitoring technology aims to detect and identify various potential abnormalities and faults, realizing real-time monitoring and early warning of dangerous situations, so as to take necessary measures for minimizing performance degradation and economic costs and avoid catastrophic situations [29-31]. Similarly, the KJ550 monitoring system can monitor the stress of coal body and rock mass in front of the working face and around the roadway in real time, and monitor and display the dynamic stress nephogram in front of the working face in real time, so as to realize the real-time monitoring and early warning of the hazardous area of rock burst. At the same time, it has the functions of remote control, data analysis and remote maintenance. Through the remote data processing and early warning center, the monitoring data can be analyzed and processed in real time.

\subsubsection{Monitoring Programme}

Figure 16 shows the layout of the 9101 working face and real-time monitoring system in Xiashanmao coal mine. It can be seen from the figure that two stations are arranged in the 9101 tail entry, and the measuring points of stations 1 and 2 are arranged in the solid coal side of the roadway to monitor the change of lateral abutment pressure of the coal side. There are four measuring points in stations 1 and 2, with buried depth of 3, 6, 9 and $12 \mathrm{~m}$ respectively; the distance between measuring points is $0.5-1 \mathrm{~m}$, and the distance between measuring station 2 and station 1 is $100 \mathrm{~m}$; Stations 3-22 are arranged in the 9101 working face to monitor the change of strike abutment pressure in working face, and each station is equipped with two measuring points with buried depths of 5 and $10 \mathrm{~m}$. The distance between stations is $2 \mathrm{~m}$ and distance between measuring points is $0.5 \mathrm{~m}$. 


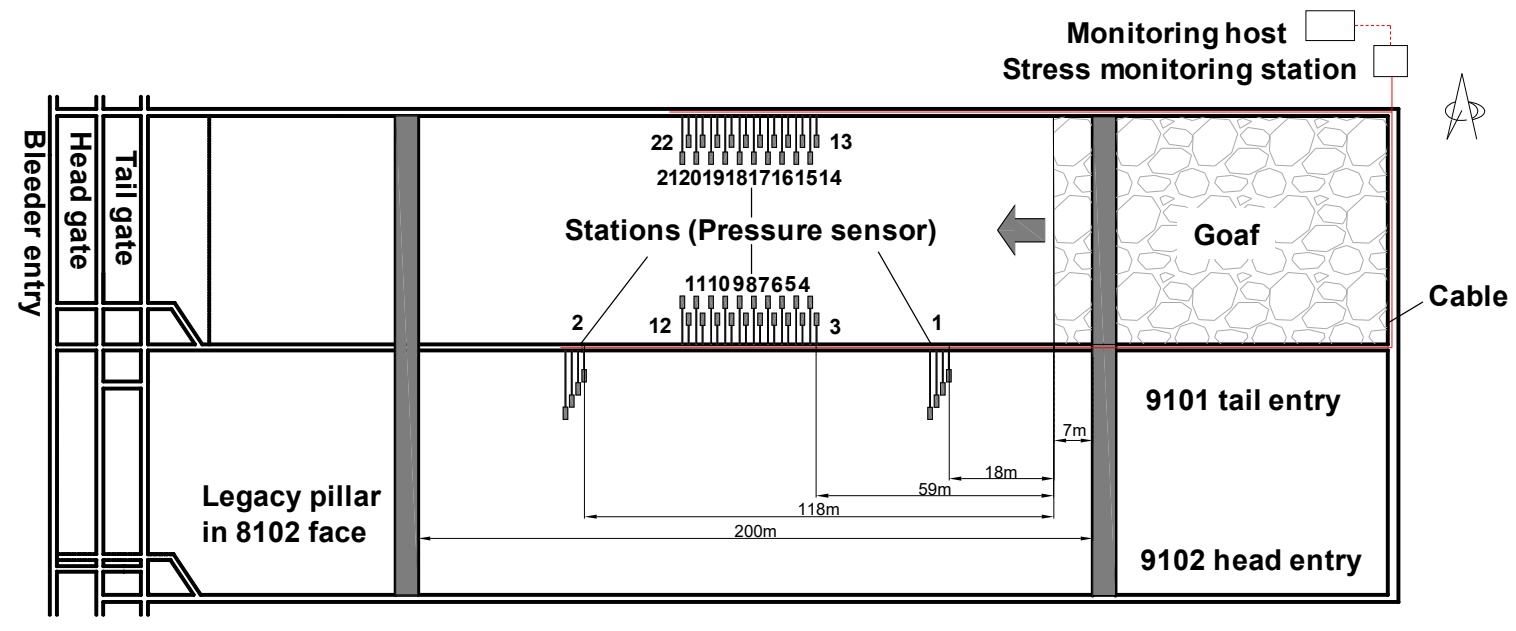

Figure 16. Layout of the 9101 working face and real-time monitoring system.

\subsection{Analysis of Main Monitoring Results}

\subsubsection{Distribution Characteristics of Strike Abutment Pressure of Working Face}

There are many stations for coal body layout in the inner side of drift in the 9101 working face. The monitoring results of two stations are selected for analysis below. Figure 17 is the relative vertical stress variation curve of each measuring point at station 3 of the lower drift and station 20 of the upper drift of the 9101 working face respectively.

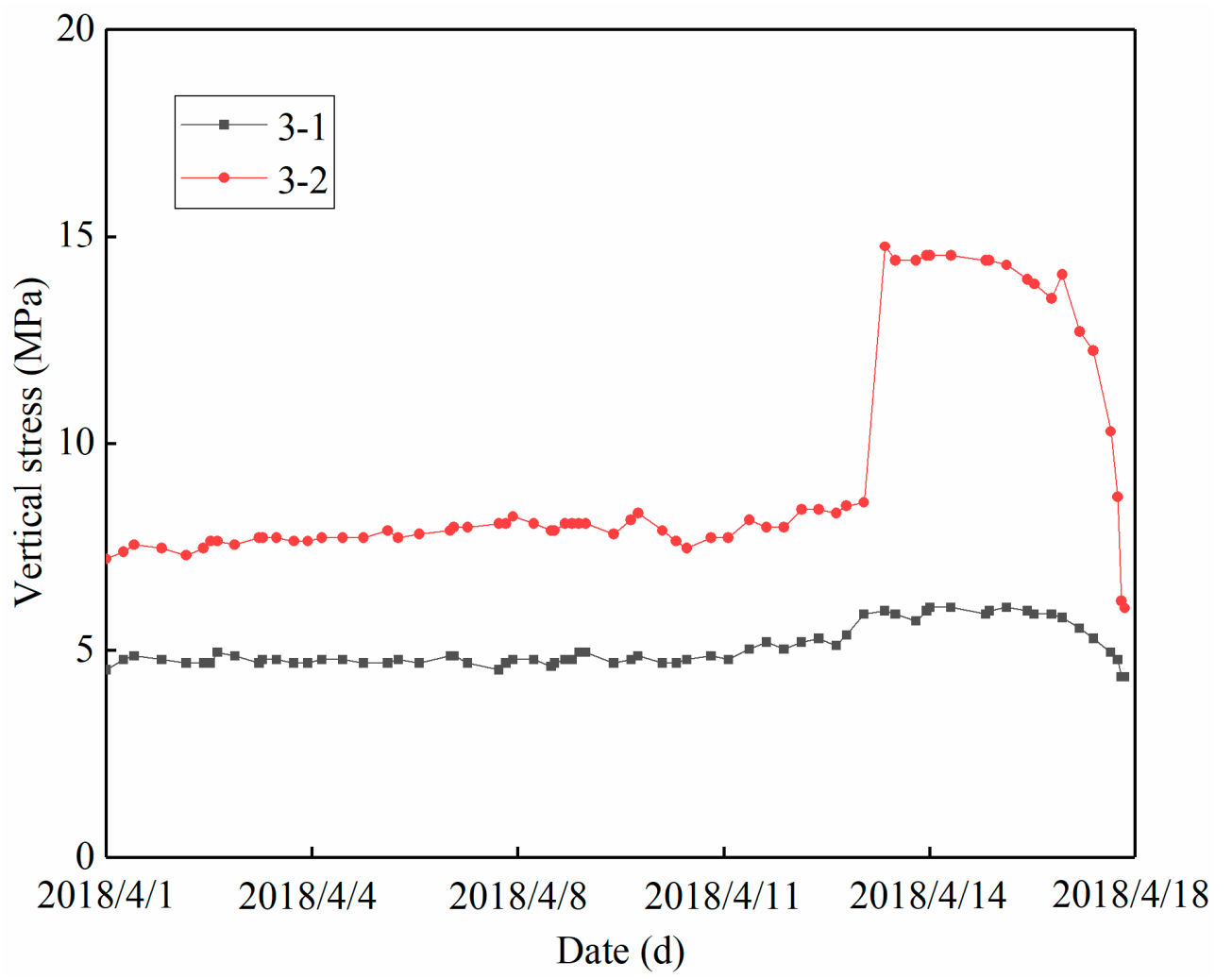

(a)

Figure 17. Cont. 


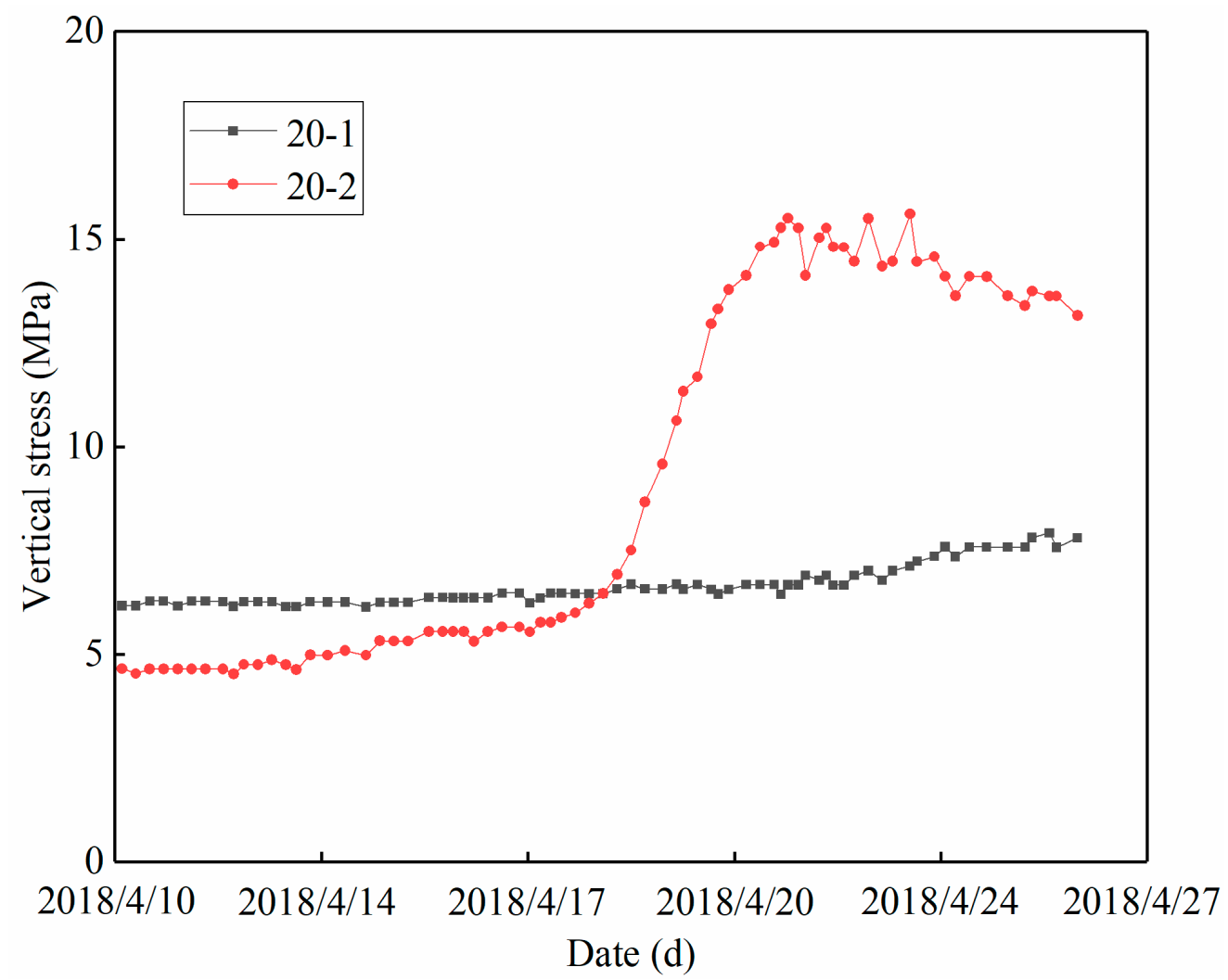

(b)

Figure 17. Relative vertical stress variation curve. (a) Relative vertical stress variation curve of station 3; (b) Relative vertical stress variation curve of station 20.

Figure 17a showed that, the vertical stress of the measuring point of the station increased significantly on $4 / 13$, indicating that the measuring point began to enter the influence range of strike abutment pressure on the working face. At this time, the measuring point was $42.6 \mathrm{~m}$ away from the working face, that is, the influence range of strike abutment pressure on working face was $42.6 \mathrm{~m}$. The vertical stress of the measuring point began to decrease on $4 / 17$, indicating that the measuring point began to enter the plastic zone, which was $9 \mathrm{~m}$ away from the working face. It could be seen that the peak position of strike abutment pressure in the working face was $9 \mathrm{~m}$ away from the coal wall, and the continuous influence distance of abutment pressure was $33.6 \mathrm{~m}$.

Figure $17 \mathrm{~b}$ showed that the vertical stress of the 20-1 measuring point began to reach the peak abutment pressure on $4 / 20$, when the measuring point was $54.2 \mathrm{~m}$ away from the working face, that is, the influence range of advance abutment pressure of the working face was $54.2 \mathrm{~m}$. The vertical stress of the measuring point began to decrease significantly on $4 / 24$, indicating that the measuring point has entered the plastic zone, which was $12 \mathrm{~m}$ away from working face, i.e., the peak position of the strike abutment pressure of the working face was $12 \mathrm{~m}$ away from the coal wall, and the continuous influence distance of the abutment pressure was $42.2 \mathrm{~m}$.

\subsubsection{Distribution Characteristics of Lateral Abutment Pressure of Working Face}

Station 1 and Station 2 were continuously monitored for 45 days (Signal cable interruption in goaf at later stage). During this period, the 9101 working face pushed forward from $18 \mathrm{~m}$ in front of station 1 to $35 \mathrm{~m}$ after station 2, with a total of $153 \mathrm{~m}$, and the distance of the signal cable entering the goaf was $60 \mathrm{~m}$. Figure 18 showed the relative vertical stress variation curves of stations 1 and 2 respectively. 


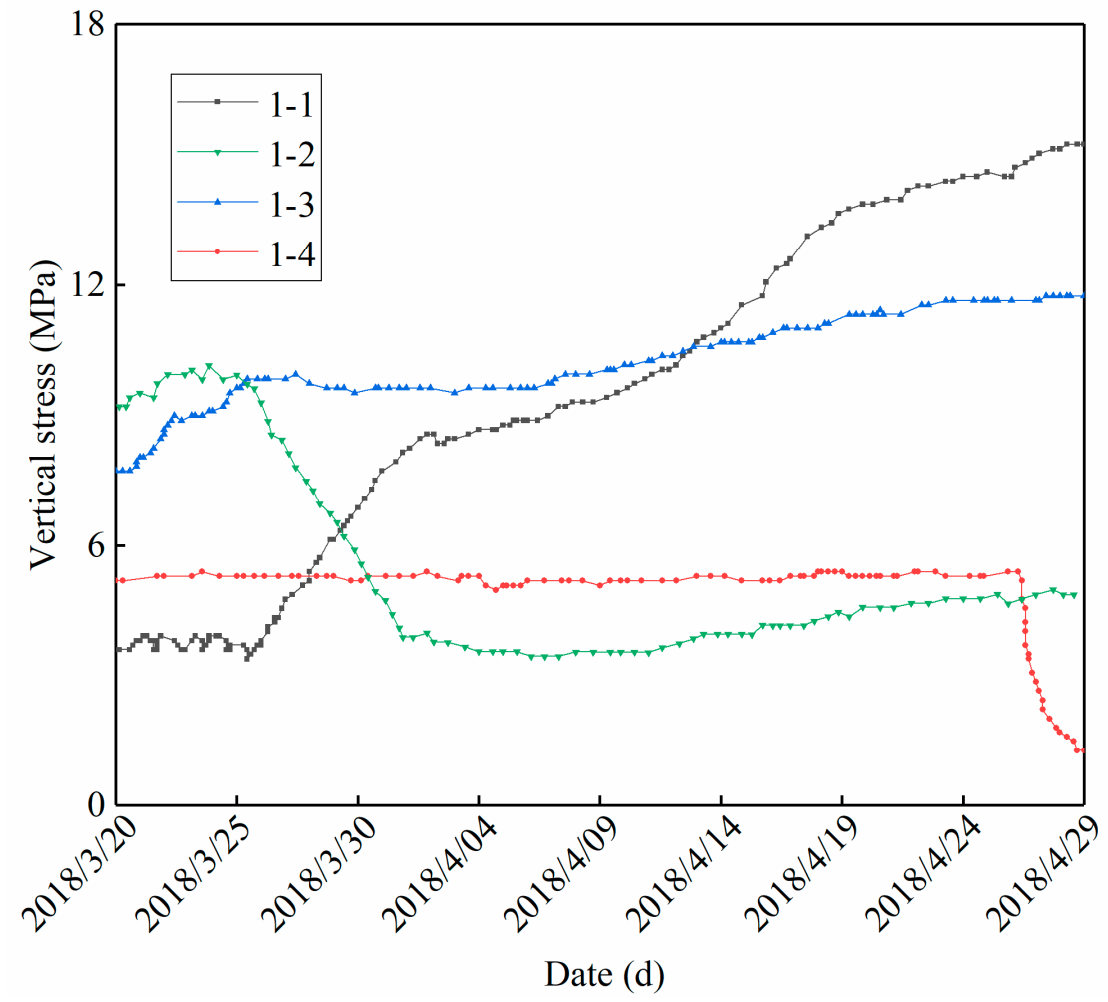

(a)

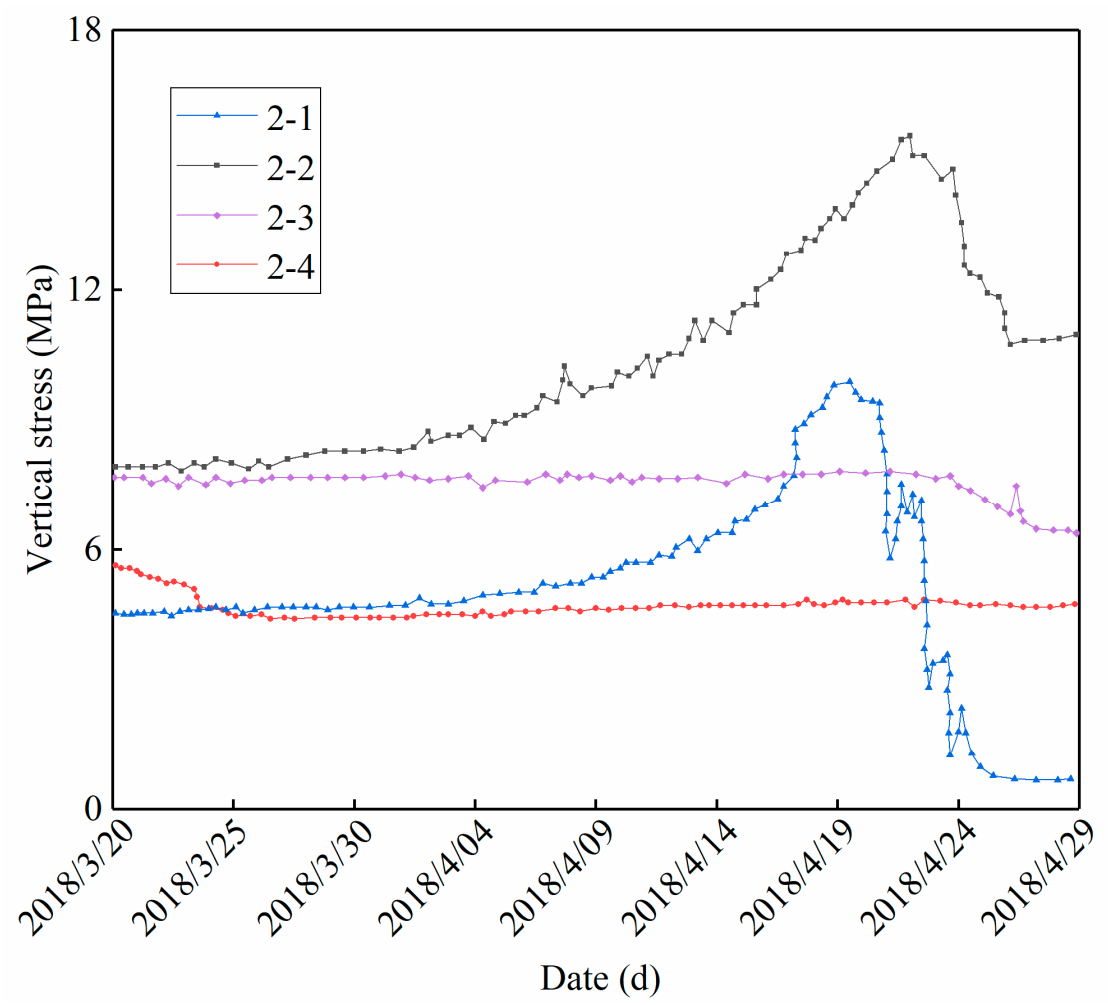

(b)

Figure 18. Relative vertical stress variation curve. (a) Relative vertical stress variation curve of station 1 ; (b) Relative vertical stress variation curve of station 2. 
Figure 18a showed that, the vertical stress of the 1-2 measuring point reached its peak on $3 / 23$, when the working face was $20 \mathrm{~m}$ ahead of the measuring point. The vertical stress of 1-3 measuring point reached the first peak on $3 / 26$, when the working face position was $3.7 \mathrm{~m}$ behind the measuring point, and began to decrease slightly on $4 / 2$, when the working face position was $40 \mathrm{~m}$ behind the measuring point. With the advancement of the working face, the vertical stress of each measuring point increased periodically. On 4/27, the vertical stresses of measuring points 1-1, 1-2 and 1-3 tended to be stable, and the vertical stress of measuring point 1-4 dropped sharply. At this time, the working face was located $60 \mathrm{~m}$ behind station 1 .

Figure $18 \mathrm{~b}$ showed that, the vertical stress of the measuring points $2-1,2-2$ and $2-3$ began to rise on $3 / 26$, when the working face was $96.3 \mathrm{~m}$ in front of station 2 , and the vertical stress of the measuring point 2-1 reached its peak on 4/19, when the working face was $19 \mathrm{~m}$ in front of the measuring point. The vertical stress of the measuring point $2-2$ reached its peak on $4 / 22$, when the working face was $3 \mathrm{~m}$ behind the measuring point. The vertical stress of measuring point 2-3 increased slightly from $4 / 17$ to $4 / 23$ and decreased considerably on $4 / 24$, when the working face advanced to $15 \mathrm{~m}$ behind the measuring point. From $4 / 18$ to $4 / 25$, the vertical stress of the $2-4$ measuring point increased slightly, then decreased slightly. At this time, the working face was located $18 \mathrm{~m}$ behind the measuring point.

\subsubsection{Comparative Analysis of Abutment Pressure}

In order to verify the numerical simulation results, the field monitoring data were compared with simulation results. When the working face advanced to station 3 , the abutment pressure in front of the working face was shown in Figure 19. The field monitoring results showed that the abutment pressure in front of the working face increased first and then decreased, reaching a peak at $9 \mathrm{~m}$ ahead of the working face, and the stress distribution tends to be stable as it was farther away from the working face. The numerical simulation results also showed the distribution law of first increasing and then decreasing, reaching the stress peak at $10 \mathrm{~m}$ ahead of the working face, and the distribution law of abutment pressure was consistent with the monitoring results.

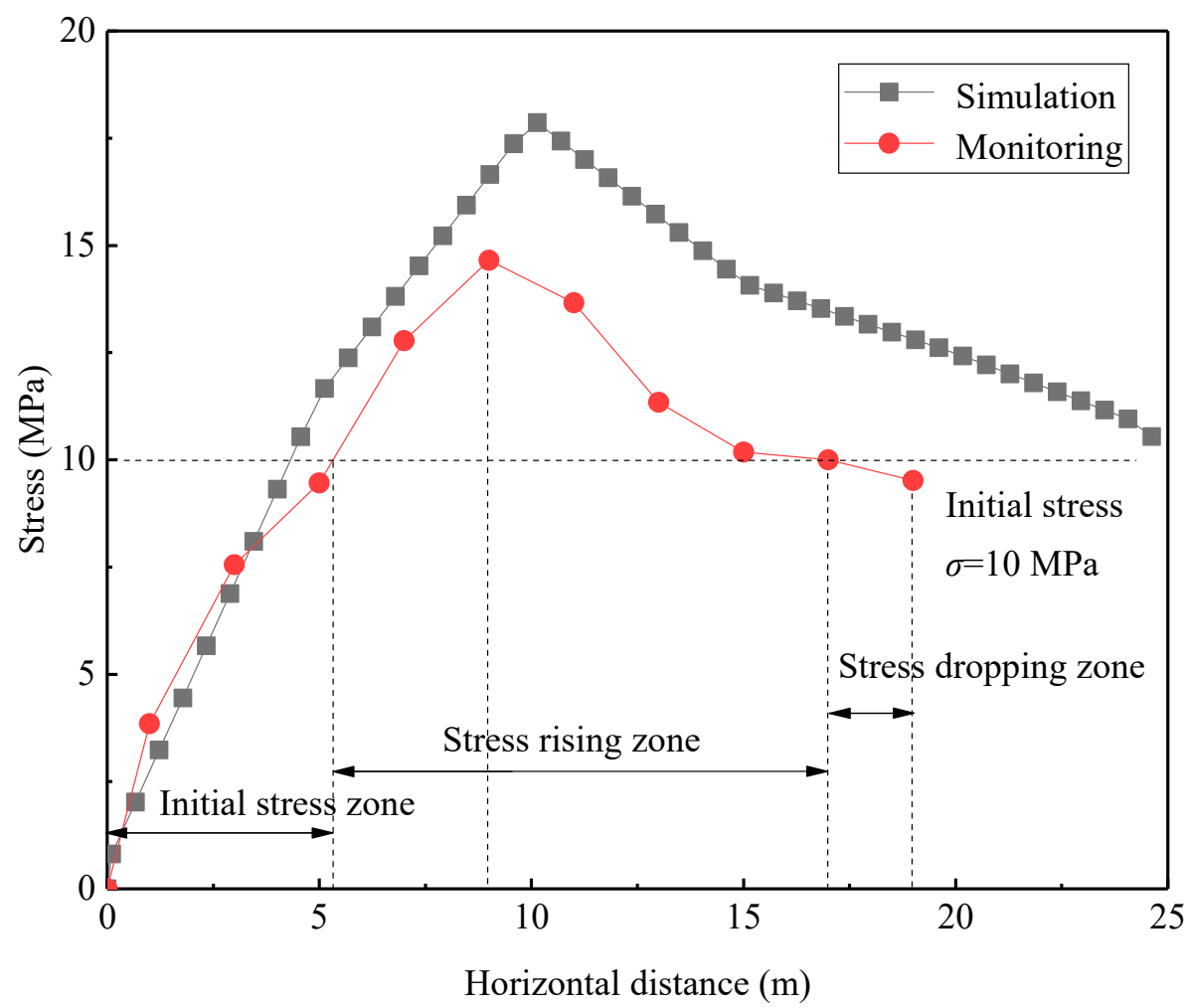

Figure 19. Distribution law of abutment pressure in front of the working face. 
When the working face advanced to $146 \mathrm{~m}$, station 2 lagged behind the working face by $28 \mathrm{~m}$. The stress data extracted from the four measuring points could reflect the distribution characteristics of lateral abutment pressure, as shown in Figure 20. Field monitoring results showed that the lateral abutment pressure of the working face continued to increase within a range of 0-6 $\mathrm{m}$ from the roadway edge, reaching a peak value of $13.7 \mathrm{MPa}$ at $6 \mathrm{~m}$, and then gradually decreased. The numerical simulation results also showed a trend of first increasing and then decreasing, and reached the peak at $5 \mathrm{~m}$ away from the roadway edge. The stress distribution law was consistent with the monitoring results.

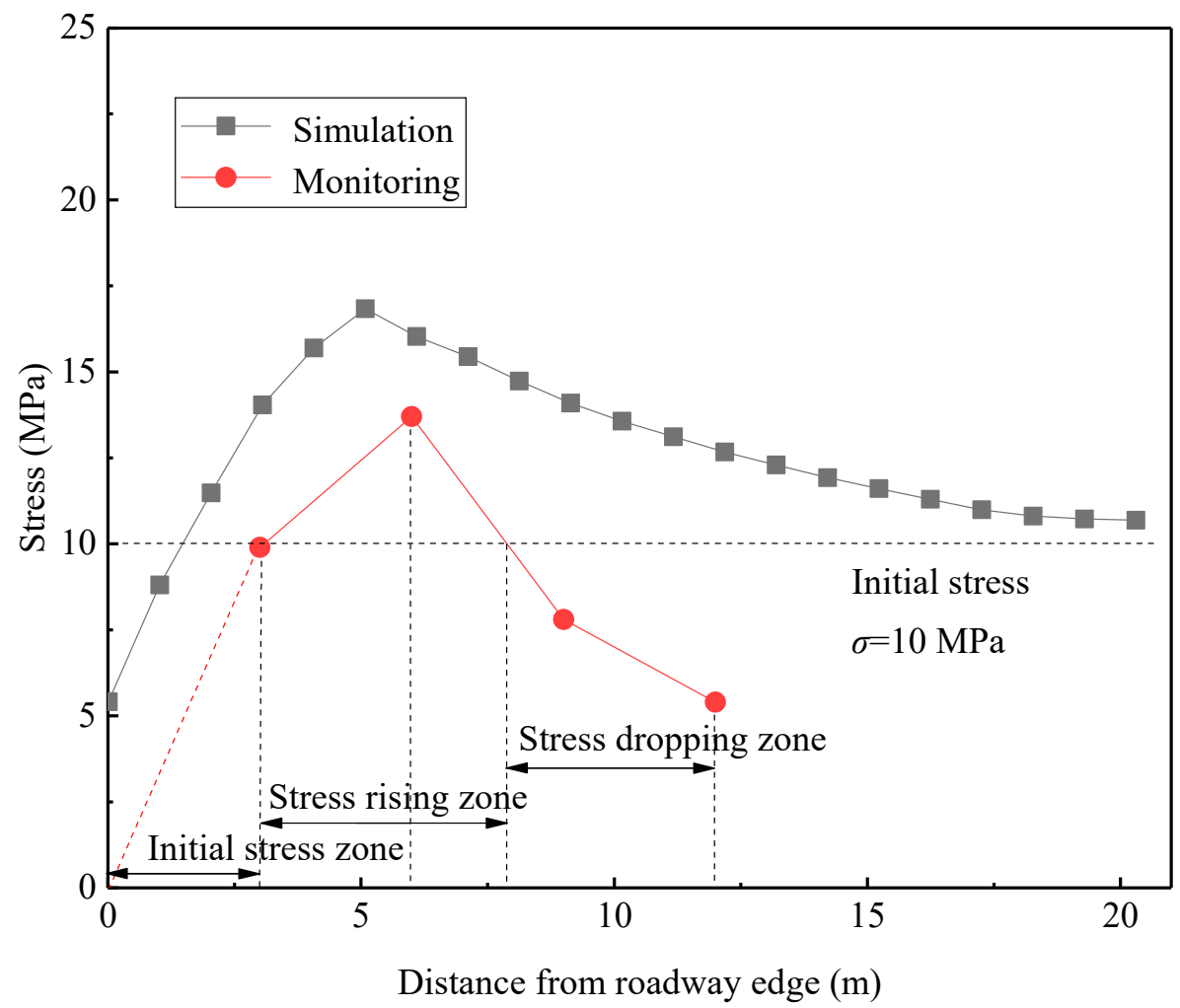

Figure 20. Distribution law of lateral abutment pressure in working face.

\section{Conclusions}

Taking Xiashanmao coal mine in Shanxi Province as the engineering background, the stress distribution in the process of coal seam mining was analyzed by establishing a numerical model, and the following conclusions were drawn:

(1) Based on the new technology of gob-side entry retaining by roof cutting without pillar, the mechanical model of the roof structure was established. Through the mechanical analysis of the model, the extension depth of the plastic zone on the solid coal side and the supporting load in the mining roadway were obtained under the condition of this technology, which provided certain theoretical support for the design of roadway support in the field.

(2) Through numerical simulation, the distributions of strike and lateral abutment pressure of the 9101 working face were obtained. Among them, the vertical stress distribution was as follows. In front of the working face: along the working face strike, the stress increased first, then decreased and then increased. The peak value of advance stress was formed at $10 \mathrm{~m}$ in front of the working face, and the peak value of non-pillar mining was reduced by $8-10 \%$ and $8-14 \%$ respectively compared with traditional mining. Along the inclination of the working face, the stress distribution of non-pillar mining and traditional mining was asymmetrical and symmetrical respectively, and the stress increased first and then decreased, while the stress at the side of roof cutting was significantly lower than that of the non-cutting. In the left side of the working face: along the inclination of the working face, the stress 
of the non-pillar mining increased at first and then decreased, while the traditional mining showed the saddle-shaped distribution characteristics, and there were one and two peak stresses respectively. The peak stress of non-pillar mining was the smallest, which was $12-21 \%$ and 3-10\% lower than that in the mining with large pillar and small pillar, respectively. The peak stress position in the former was closer to the mining roadway.

The horizontal stress distribution was as follows. In front of the working face: The stresses of the three increased first and then decreased. The peak position was $10 \mathrm{~m}$ ahead of the working face, in which the area, span and peak value of the stress rising area under large pillar mining were the largest, while those of non-pillar mining were the smallest. In the left side of the working face: high stress concentration was formed in the large pillar, not obvious in the small pillar, but a large area of stress concentration was formed in the 9102 working face. Because of the technology of roof cutting and retaining roadway, the phenomenon of stress increase appeared in the 9102 working face for non-pillar mining, but the area of the concentrated area was lower than that of traditional mining.

The results show that, in front of the working face: The stress increase area and peak stress of non-pillar mining were smaller than that of traditional mining. Around the retaining roadway, the stress transfer between roof rock beams was cut off by the roof cutting and pressure relief, which effectively weakens the stress concentration in deep surrounding rock. In the left side of the working face: The number of stress peaks was small and the peak stress was small for non-pillar mining. The stress-bearing areas of three mining methods were different, which were big coal pillar of large pillar mining, 9102 working face of small pillar mining and 9102 working face of non-pillar mining. The width of the plastic zone of surrounding rock of non-pillar mining was smaller and the bearing capacity was higher.

(3) The mine pressure monitoring data showed that the influence range of strike abutment pressure of the working face was $42.6-54.2 \mathrm{~m}$. The distance between the peak position of abutment pressure and coal wall was $9-12 \mathrm{~m}$. The sustained influence distance of abutment pressure was $33.6-42.2 \mathrm{~m}$. The peak value of vertical stress at the deep-buried measuring point lagged behind that at the shallow-buried one. In the lateral side of the working face, the influence distance of mining in front of the 9101 working face was $48 \mathrm{~m}$. With the advancement of the working face, the influence on it became more and more serious. The breaking and rotation of the hard strata overlying the working face caused the vertical stress of the shallow buried measuring point to rise. When $86 \mathrm{~m}$ ahead of the station, the stress at the measuring point was basically not affected by mining and reached a stable state. By comparing the field mine pressure monitoring results with the numerical simulation results, it could be found that the simulation results were consistent with the monitoring results.

Author Contributions: X.S. and Y.L. conceived and designed the research. Y.L. performed the numerical simulation. S.S. was involved in the construction of numerical model. J.W., X.C. and J.L. were involved in the numerical simulation. Y.L. analyzed the data and wrote the paper.

Funding: This work was supported by the National Key Research and Development Plan of China (2016YFC0600901), the National Natural Science Foundation of China (Grant No. 51874311), the Special Fund of Basic Research and Operating of China University of Mining \& Technology, Beijing (Grant No. 2009QL03), which are gratefully acknowledged.

Conflicts of Interest: The authors declare no conflict of interest.

\section{References}

1. Qian, M.G. The equilibrium condition of overlying strata in stope. J. China Min. Univ. 1981, 2, $34-43$.

2. Song, Z.Q. The basic law of overlying strata movement in stope. J. Shandong Min. Univ. 1979, 1, 64-77.

3. Zhu, Z.Q.; Song, Y.; Liu, Y.X.; Chen, M.B.; Hua, Y.F. The behavior regularity law and application of abutment pressure in stope. J. Shandong Min. Univ. 1982, 1, 1-25.

4. He, M.C.; Zhu, G.L.; Guo, Z.B. Longwall mining "cutting cantilever beam theory" and 110 mining method in China-The third mining science innovation. J. Rock Mech. Geotech. Eng. 2015, 5, 483-492. [CrossRef] 
5. Zhang, G.F.; He, M.C.; Yu, X.P.; Huang, Z.G. Research on the technique of non-pillar mining with gob-side entry formed by advanced roof caving in the protective seam in Baijiao coal mine. J. Min. Saf. Eng. 2011, 28, 511-516.

6. Yang, J.; He, M.C.; Cao, C. Design principles and key technologies of gob side entry retaining by roof pre-fracturing. Tunn. Space Technol. 2019, 90, 309-318. [CrossRef]

7. Gao, Y.B.; Wang, Y.J.; Yang, J.; Zhang, X.Y.; He, M.C. Meso-and macroeffects of roof split blasting on the stability of gateroad surroundings in an innovative nonpillar mining method. Tunn. Space Technol. 2019, 90, 99-118. [CrossRef]

8. Wang, Q.; He, M.C.; Yang, J.; Gao, H.K.; Jiang, B.; Yu, H.C. Study of a no-pillar mining technique with automatically formed gob-side entry retaining for longwall mining in coal mines. Int. J. Rock Mech. Min. Sci. 2018, 110, 1-8. [CrossRef]

9. Guo, Z.B.; Zhang, L.; Ma, Z.B.; Zhong, F.X.; Yu, J.C.; Wang, S.M. Numerical investigation of the influence of roof fracturing angle on the stability of gob-side entry subjected to dynamic loading. Shock Vib. 2019, 2019, 1434135. [CrossRef]

10. Zhen, E.Z.; Gao, Y.B.; Wang, Y.J.; Wang, S.M. Comparative study on two types of nonpillar mining techniques by roof cutting and by filling artificial materials. Adv. Civ. Eng. 2019, 2019, 5267240. [CrossRef]

11. Guo, Z.B.; Wang, Q.; Li, Z.H.; He, M.C.; Ma, Z.B.; Zhong, F.X.; Hu, J. Surrounding rock control of an innovative gob-side entry retaining with energy-absorbing supporting in deep mining. Int. J. Low Carbon Technol. 2019, 14, 23-35. [CrossRef]

12. Hu, J.Z.; He, M.C.; Wang, J.; Ma, Z.M.; Wang, Y.J.; Zhang, X.Y. Key parameters of roof cutting of gob-side entry retaining in a deep inclined thick coal seam with hard roof. Energies 2019, 12, 934. [CrossRef]

13. Singh, G. Assessment of goaf characteristics and compaction in longwall caving. Min. Technol. 2011, 120, 222-232. [CrossRef]

14. Zhu, Z.; Zhu, C.; Yuan, H. Distribution and evolution characteristics of macroscopic stress field in gob-Side entry retaining by roof cutting. Geotech. Geol. Eng. 2019, 37, 2963-2976. [CrossRef]

15. Zhang, C.L.; Yu, L.; Feng, R.M.; Zhang, Y.; Zhang, G.J. A numerical study of stress distribution and fracture development above a protective coal seam in longwall mining. Processes 2018, 6, 146. [CrossRef]

16. Liu, X.J.; Li, X.M.; Pan, W.D. Analysis on the floor stress distribution and roadway position in the close distance coal seams. Arab. J. Geosci. 2016, 9, 83-91.

17. Zhang, W.; Zhang, D.S.; Qi, D.H.; Hu, W.M.; He, Z.M.; Zhang, W.S. Floor failure depth of upper coal seam during close coal seams mining and its novel detection method. Energy Explor. Exploit. 2018, 36, 1265-1278. [CrossRef]

18. Xu, Y.L.; Pan, K.R.; Zhang, H. Investigation of key techniques on floor roadway support under the impacts of superimposed mining: Theoretical analysis and field study. Environ. Earth Sci. 2019, 78, 436-450. [CrossRef]

19. Wang, P.; Zhao, J.; Feng, G.; Wang, Z. Interaction between vertical stress distribution within the goaf and surrounding rock mass in longwall panel systems. J. S. Afr. Inst. Min. Metall. 2018, 118, 745-756. [CrossRef]

20. Ma, C.Q.; Wang, P.; Jiang, L.S.; Wang, C.S. Deformation and control countermeasure of surrounding rocks for water-dripping roadway below a contiguous seam goaf. Processes 2018, 6, 77. [CrossRef]

21. Liu, C.Y.; Yang, J.X.; Yu, B.; Yang, P.J. Destabilization regularity of hard thick roof group under the multi gob. J. China Coal Soc. 2014, 39, 395-403.

22. Huang, Q.X.; Cao, J.; He, Y.P. Analysis of roof structure and support load of mining face under ultra-close goaf in shallow multiple seams. Chin. J. Rock Mech. Eng. 2018, 37, 3153-3159.

23. Yang, K.; He, X.; Liu, S.; Lu, W. Rib spalling mechanism and control with fully mechanized longwall mining in large inclination "three-soft" thick coal seam under closed distance mined gob. J. Min. Saf. Eng. 2016, 33, 611-617.

24. Gao, Z.W.; Saxen, H.; Gao, C.H. Special section on data-driven approaches for complex industrial systems. IEEE Trans. Ind. Inform. 2013, 9, 2210-2212. [CrossRef]

25. He, M.C.; Gong, W.L.; Wang, J.; Qi, P.; Tao, Z.G.; Du, S.; Peng, Y.Y. Development of a novel energy-absorbing bolt with extraordinarily large elongation and constant resistance. Int. J. Rock Mech. Min. Sci. 2014, 67, $29-42$. [CrossRef]

26. He, M.C.; Li, C.; Gong, W.L.; Sousa, L.R.; Li, S.L. Dynamic tests for a Constant-Resistance-Large-Deformation bolt using a modified SHTB system. Tunn. Space Technol. 2017, 64, 103-116. [CrossRef] 
27. Li, Y.F.; Hua, X.Z.; Cai, R.C. Mechanics analysis on the stability of key block in the gob-side entry retaining and engineering application. J. Min. Saf. Eng. 2012, 29, 357-364.

28. Lee, C.J.; Wu, B.R.; Chen, H.T.; Chiang, K.H. Tunnel stability and arching effects during tunneling in soft clayey soil. Tunn. Space Technol. 2006, 21, 119-132. [CrossRef]

29. Gao, Z.W.; Ding, S.X.; Cecati, C. Real-time fault diagnosis and fault-tolerant control. IEEE Trans. Ind. Electron. 2015, 62, 3752-3756. [CrossRef]

30. Gao, Z.W.; Sheng, S.W. Real-time monitoring, prognosis, and resilient control for wind turbine systems. Renew. Energy 2018, 116, 1-4. [CrossRef]

31. Tadisetty, S.; Matsui, K.; Shimada, H.; Gupta, R.N. Real time analysis and forecasting of strata caving behaviour during longwall operations. Rock Mech. Rock Eng. 2006, 39, 383-393. [CrossRef]

(C) 2019 by the authors. Licensee MDPI, Basel, Switzerland. This article is an open access article distributed under the terms and conditions of the Creative Commons Attribution (CC BY) license (http://creativecommons.org/licenses/by/4.0/). 